\title{
Integration of lakes and streams in a landscape perspective: the importance of material processing on spatial patterns and temporal coherence
}

\author{
GEORGE W. KLING*, GEORGE W. KIPPHUT, † MICHAEL M. MILLER AND W. JOHN O’BRIEN§ \\ *Department of Biology, University of Michigan, Ann Arbor, MI 48109, U.S.A. \\ †Department of Geosciences, Murray State University, Murray, KY 42071, U.S.A. \\ $\ddagger$ Department of Biological Sciences, University of Cincinnati, Cincinnati, OH 45221, U.S.A. \\ §Department of Ecology and Systematics, University of Kansas, Lawrence, KS 66045, U.S.A.
}

\section{SUMMARY}

1. We studied the spatial and temporal patterns of change in a suite of twenty-one chemical and biological variables in a lake district in arctic Alaska, U.S.A. The study included fourteen stream sites and ten lake sites, nine of which were in a direct series of surface drainage. All twenty-four sites were sampled between one and five times a year from 1991 to 1997.

2. Stream sites tended to have higher values of major anions and cations than the lake sites, while the lake sites had higher values of particulate carbon, nitrogen, phosphorous and chlorophyll $a$. There were consistent and statistically significant differences in concentrations of variables measured at the inlet versus the outlet of lakes, and in variables measured at upstream versus downstream sites in the stream reaches which connect the lakes. In-lake processing tended to consume alkalinity, conductivity, $\mathrm{H}^{+}, \mathrm{DIC}, \mathrm{Ca}^{2+}, \mathrm{Mg}^{2+}$, $\mathrm{CO}_{2}, \mathrm{CH}_{4}$, and $\mathrm{NO}_{3}{ }^{-}$, and produce $\mathrm{K}^{+}$and dissolved organic carbon (DOC). In-stream processing resulted in the opposite trends (e.g. consumption of $\mathrm{K}^{+}$and $\mathrm{DOC}$ ), and the magnitudes of change were often similar to those measured in the lakes but with the opposite sign.

3. Observed spatial patterns in the study lakes included mean concentrations of variables which increased, decreased or were constant along the lake chain from high to low altitude in the catchment (stream sites showed no spatial patterns with any variables). The strongest spatial patterns were of increasing conductivity, $\mathrm{Ca}^{2+}, \mathrm{Mg}^{2+}$, alkalinity, dissolved inorganic carbon and $\mathrm{pH}$ with lake chain number (high to low altitude in the basin). These patterns were partly determined by the effect of increasing catchment area feeding into lakes further downslope, and partly by the systematic processing of materials in lakes and in the stream segments between lakes.

4. Synchrony (the temporal coherence or correlation of response) of variables across all lakes ranged from 0.18 for particulate phosphorus to 0.90 for $\mathrm{Mg}^{2+}$; the average synchrony for all twenty-one variables was 0.50 . The synchronous behaviour of lake pairs was primarily related to the spatial location or proximity of the lakes for all variables taken together and for many individual variables, and secondarily, to the catchment to lake area ratio and the water residence time.

5. These results illustrate that, over small geographic areas, and somewhat independent of lake or stream morphometry, the consistent and directional (downslope) processing of

Correspondence: George W. Kling, Department of Biology, University of Michigan, Ann Arbor 48109-1048, MI, U.S.A.

E-mail: gwk@umich.edu 
materials helps produce spatial patterns which are coherent over time for many limnological variables. We combine concepts from stream, lake and landscape ecology, and develop a conceptual view of landscape mass balance. This view highlights that the integration of material processing in both lakes and rivers is critical for understanding the structure and function of surface waters, especially from a landscape perspective.

Keywords: lakes, landscape ecology, mass balance, rivers, spatial pattern, synchrony

\section{Introduction}

One of the principles of ecological investigations is that most descriptors of a system vary with the spatial or temporal scale of measurement. In biological studies, the spatial and temporal heterogeneity of organisms is a central component of several theories (e.g. evolution and succession), and new advances in understanding the consequences of environmental heterogeneity on biological systems have been made in the last 20-30 years. These advances include: (1) the development of statistics and quantitative modelling of spatial patterns in landscape ecology (Cliff \& Ord, 1973; Legendre \& Fortin, 1989; Turner \& Gardner, 1991; Hargis, Bissonette \& David, 1998); (2) the establishment of metapopulation dynamics and its guiding role in conservation biology (Levins, 1969; Hanski \& Gilpin, 1991; With, 1997); (3) the concept of hierarchy structure in ecosystems (O'Neill et al., 1986); and (4) models describing temporal synchrony and patch dynamics in both terrestrial and aquatic systems (Platt \& Denman, 1975; Kratz et al., 1991; Moloney, Morin \& Levin, 1991; Levin, Powell \& Steele, 1993; Powell \& Steele, 1995). These advances illustrate the importance of both deriving the relationship between process and pattern, and using models to predict or extrapolate across new scales.

Through studies in landscape ecology we have also learned that in addition to the spatial distribution or patchiness of resources and organisms, the movement of organisms and the 'connectivity' among patches is critical to system functioning (Casti, 1979; Hansen \& di Castri, 1992; Taylor et al., 1993). In studies of temporal dynamics, organisms are considered to adapt and evolve, and characteristics of the environment (e.g. soil properties) are considered to change from one time period to another. These temporal dynamics may be controlled in part by location in space; for example, as demonstrated by studies of the synchrony of characteristics in lakes found at different positions on the landscape (Magnuson, Benson \& Kratz, 1990; Soranno et al., 1999). However, in studies of system function across spatial scales, the environmental characteristics and organisms of interest are usually considered to be static. In other words, the rates of movement of organisms or materials may be affected by the boundaries or ecotones which separate different environmental patches, but there is little or no change, or 'processing', which occurs as materials and organisms move across the landscape.

There are two main exceptions to this generalization of an assumed lack of processing of materials moving across a landscape, one derived from concepts in stream ecology and one from studies of landscape position in lakes. The first exception incorporates the 'river continuum concept' (RCC; Vannote et al., 1980), the 'serial discontinuity' concept (Ward \& Standford, 1983) and the 'resource spiralling' concept (Newbold et al., 1981). The RCC is founded on the idea that the functioning of rivers is partly driven by their changing physical structure as they flow from headwaters to the river mouth and partly by the attending processing of materials along this flowpath across space. If the river flowpath is interrupted (e.g. by a reservoir or series of reservoirs), a 'serial discontinuity' results which will alter the structure and function of downstream lotic ecosystems; the nature of the alteration is dependent on the stream order, and hence, linked explicitly to the predictions of the RCC. Although the concept of resource spiralling predicts that the cycling of materials in flowing waters is spatially dependent, the predictions are usually applied to smaller scales than those of the RCC, on the order of tens to thousands of meters of a river reach. The second set of studies which considers spatially dependent material processing includes the recognition that, as one moves downslope within a drainage basin, an increase in the contact time of groundwater with soils leads to a build up of weathering products in lakes positioned lower 
in the landscape (Magnuson et al., 1990; Kratz et al., 1997; Soranno et al., 1999).

While these ideas about spatially-dependent processes in rivers and lakes have had great utility in aquatic ecology, there has been very little empirical or conceptual integration of lakes and rivers at a landscape level. For example, the serial discontinuity concept considers that the reservoirs separating stream segments are 'theoretical dimensionless points on the longitudinal stream profile' (Ward \& Standford, 1983); thus, the reservoirs represent a sharp step change in conditions, analogous to the concept of narrow ecotones in landscape ecology (Hansen, Risser \& di Castri, 1992). On the other hand, the approach in lake and reservoir studies has been to model a series of impoundments as individual 'reactors' which are connected by intervening stream segments which move only water and themselves impart no change to the water through processing (Lerman, 1972; Chapra \& Reckhow, 1983; Elser \& Kimmel, 1985; Vörösmarty et al., 1997a,b). While these approaches can describe well the functioning of individual systems, there is a large amount of residual variation among lakes and among streams which may only be explained through an understanding of ecosystem interactions at a landscape scale.

We propose that current concepts related to the functioning of aquatic ecosystems within a landscape can be placed in a broader theoretical context by including the spatially dependent processing of materials in both lakes and streams taken together. The foundation of this idea is the concept of a 'mass balance budget', which allows determination of the changes in mass of substances (or the number of organisms) in a defined space and time, and requires only information on 'pools' of variables such as populations or standing stocks of materials, and on processes which control the flows, production, consumption and transformation of the variables (see Fisher \& Likens, 1973; Vollenweider, 1975; Chapra \& Reckhow, 1983). Mass balance models may be simple, where any number of processes are implicitly subsumed into a 'black box', or detailed, with explicit mechanistic formulations. Each of the important processes defined by the ecological concepts described above may be represented in a mass balance format; for example, an ecotone such as a riparian zone is a pool considered to have inputs from other pools of material in the model, such as an upland area, and then specific production or consumption processes affect those inputs, and contribute to a flow or output into an adjoining pool of material such as a stream.

At these initial stages of development of this landscape mass balance concept, we contribute only information on the importance of linking lakes and rivers, partly because there are too few data available on the stocks, flows and transformations of materials in a series of lakes and streams to build a quantitative model. Here we present an empirical study of how the processing of materials moving across a landscape influences the spatial patterns of limnological variables in a series of lakes in arctic Alaska, U.S.A. We integrate the effects of processing in lakes and in streams into the concept of landscape mass balance, and we show that consistent changes occurring along the downslope flowpath within stream segments which connect lakes, and changes within the lakes themselves, contribute to the spatial patterns and synchronous behaviour of various solute and particulate concentrations in the surface waters.

\section{Methods}

\section{Site description}

The Toolik Lake area is located in the northern foothills of the Brooks Range, Alaska, U.S.A., $\approx 180 \mathrm{~km}$ south of the Arctic Ocean, and is the site of the Arctic Long-Term Ecological Research (LTER) project. The catchment draining into Toolik Lake, the largest lake in the area, covers $66.9 \mathrm{~km}^{2}$ and is subdivided into several sub-basins containing many small lakes and about nineteen lakes greater than 1 ha in surface area. The largest sub-basin is $46.6 \mathrm{~km}^{2}$ in area, and contains the main surface inlet to Toolik Lake and the lakes reported on in this study. These lakes are connected by surface streams which eventually feed into the main inlet which flows into the south-eastern part of Toolik Lake (Fig. 1). Table 1 presents the morphometric data for this inlet series of lakes and their individual catchments. The lakes lie between latitude $68^{\circ} 34^{\prime}$ to $68^{\circ} 38^{\prime} \mathrm{N}$ and longitude $149^{\circ} 32^{\prime}$ to $149^{\circ} 37 \mathrm{E}$. All of the lakes were formed by glaciation $\approx 10000-12000$ years ago and lie mainly in a glacial outwash valley. The lakes are surrounded by low, rolling hills covered with sedges and grasses dominated by cotton grass, mixed with dwarf birch, low willows and various forbs. There are two ages of land surface in the basin: (1) an older surface on the 
ridges and highlands which was last glaciated $\approx 100000$ years ago; and (2) a younger surface in the lowlands and valleys which was influenced by the most recent glaciation $\approx 10000$ years ago (Hamilton \& Porter, 1975).

The inlet stream to Toolik Lake consists of two major branches (Fig. 1). The first branch on the western part of the basin includes a series of eight lakes, I-1 to I-7 and I-Swamp. This branch begins with two headwater lakes, I-1 and I-2, and the outlets of both of these lakes feed into Lake I-3. Lake I-6 also has two major inlets, one from Lake I-5 and a second stream site called I-6 West. The main second branch begins in the headwaters of the eastern part of the basin at the stream site called I-8 Headwaters (Fig. 1). This stream flows through tundra for its entire length until it reaches Lake I-8, which is the only lake on this eastern stream branch. The eastern and western branches meet at site I-9, which is a small, shallow pool on the main inlet stream. Downstream of this shallow I-9 pool, the Milky Way stream enters the Toolik inlet; the Milky Way is so named because of the water of high carbonate content which it contains, which is derived from water flowing through a large gravel pad which was used during the construction of the Alaskan oil pipeline in the 1970s. Both branches

\begin{tabular}{|ll|}
\hline $\begin{array}{l}\text { Series } \\
\text { Number }\end{array}$ & \multicolumn{1}{c|}{ Site } \\
\hdashline-1 & Name \\
\hline 1 & I-8 Headwater \\
2 & I-2 \\
3 & I-1 \\
4 & I-1 to I-3 \\
5 & I-2 to I-3 \\
6 & I-3 \\
7 & I-4 \\
8 & I-4 to I-5 \\
9 & I-5 \\
10 & I-5 to I-6 \\
11 & I-6 West \\
12 & I-6 \\
13 & I-7 \\
14 & I-8 In \\
15 & I-8 \\
16 & I-Swamp In \\
17 & I-Swamp \\
18 & I-7 to I-9 \\
19 & I-8 to I-9 \\
20 & I-9 \\
21 & Milky Way Lower \\
22 & Toolik Inlet \\
23 & Toolik Main \\
24 & Milky Way Upper \\
& \\
\hline
\end{tabular}

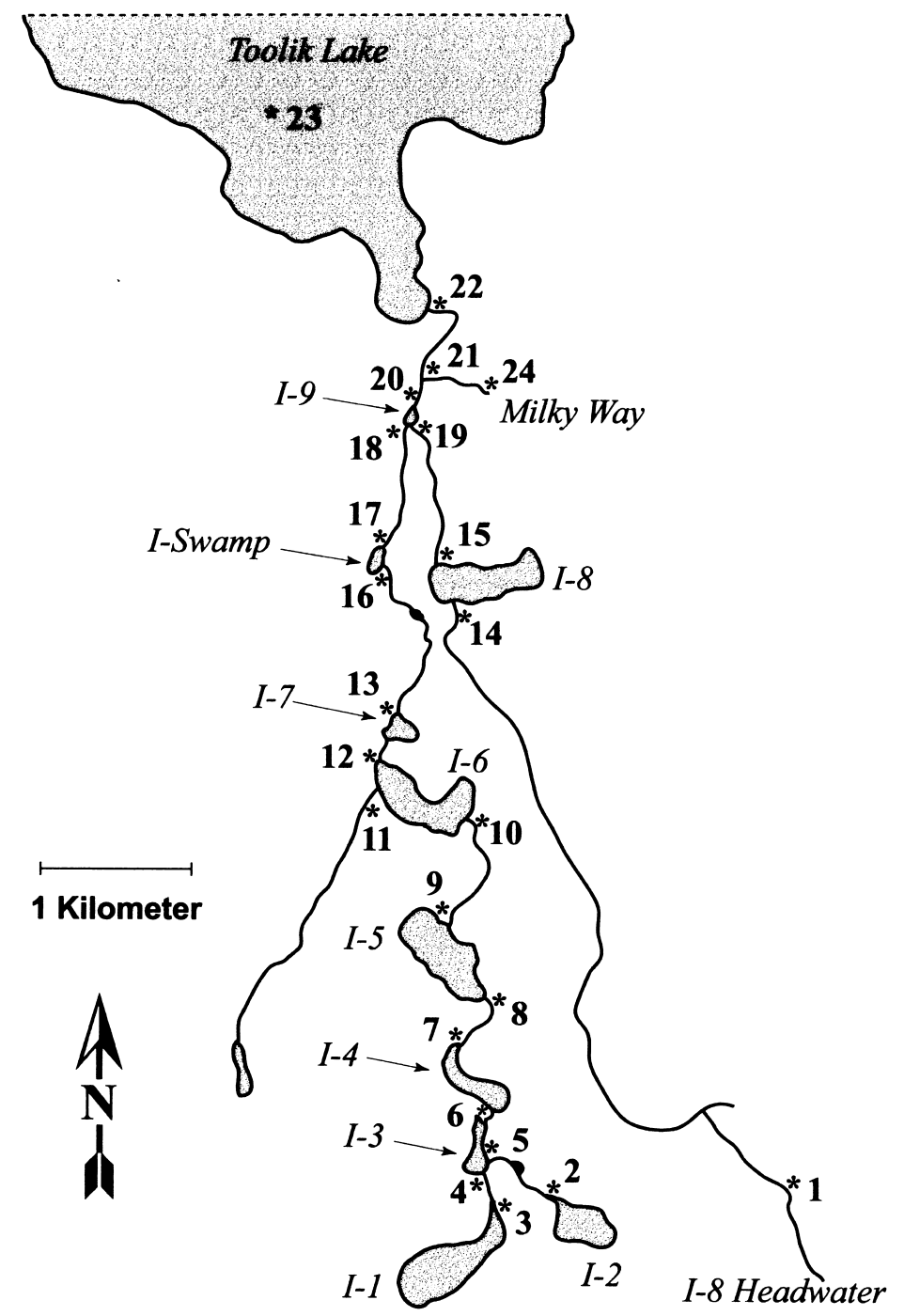

Fig. 1 Map of the longest series of streams and lakes entering into Toolik Lake, arctic Alaska. Series numbers correspond to the data presented in Table 5. Lake numbers are different from series numbers and are given in Table 1 for the ten lakes studied in this subbasin. 
have the same altitudinal change of $66 \mathrm{~m}$ from the headwater lakes to Toolik Lake (Table 1). The 'lake chain number' used to identify the connected lakes is equivalent to lake altitude, except that Lake I-8 is at the same altitude as I-7, but I-8 is not in the lake chain (Fig. 1).

The lakes range in size from 1.9 to 149 ha (mean $\pm \mathrm{SE}=25.0 \pm 14.0$ ) and in depth from 4.9 to $25 \mathrm{~m}$ (mean $\pm \mathrm{SE}=11.8 \pm 1.9$ ). Spring runoff of melting snow begins in mid- to late May, while the lakes are still ice covered; the lakes thaw up to a month later, from mid- to late June, and freeze in late September. Deep groundwater flow is unimportant for these lakes because the soils thaw to depths of only $0.3-1.0 \mathrm{~m}$ during the summer. In addition, this shallow thaw causes $\approx 90 \%$ of the soil water to flow through the upper organic layer rather than through deeper mineral soil of low hydraulic conductivity (Hinzman et al., 1991). The water residence time (WRT) for Toolik Lake is $\approx 1$ year (see the discussion of how the complex morphology of Toolik influences WRT in O'Brien et al., 1997). Although WRT is unmeasured in the other lakes, the similarity in climate, geology, permafrost soils and vegetation within the entire basin allows us to estimate minimum WRT by comparing the ratio of lake volume to drainage area of each lake to that of Toolik Lake.
Thus, if a lake has a small volume and a large drainage area relative to Toolik, the WRT will be shorter than the 1-year value measured for Toolik Lake (Table 1$)$. The mean WRT $( \pm$ SE) of all ten lakes was $1.7 \pm 0.4$ years.

The entire inlet series of lakes and their connecting inlet and outlet streams were usually sampled during one day, and sometimes during two consecutive days. Measures of primary productivity in the lakes occurred in 1989, and a survey of lakes I-6 and I-8 occurred in 1990. Full sampling of all sites occurred once in 1991, four times in 1992, five times in 1993, three times each in 1994 and 1995, and two times each in 1996 and 1997. In addition, beginning in 1993 during most of June and August and all of July, weekly or biweekly samples were collected from Toolik Inlet, Milky Way, and the main eastern and western stream branches as these enter I-9. Most collections of lake surface waters were taken using the lake outlet as an integrated sample of epilimnetic water. To test how representative this sampling procedure was, outlet samples were taken on the same days that depth profiles were taken from the centre of eight different lakes. The outlet values for conductivity, $\mathrm{pH}$, alkalinity, $\mathrm{CO}_{2}, \mathrm{Ca}^{2+}, \mathrm{Mg}^{2+}, \mathrm{Na}^{+}$, and $\mathrm{K}^{+}$were very similar to the integrated epilimnion values from the same days $(n=80$ comparisons, mean

Table 1 Location, morphometric data and estimates of water residence time (WRT) for the series of lakes in the Toolik Lake catchment. (Note that lake chain number in this table is different from series number in Fig. 1.) The cumulative catchment area for the series of lakes from I-1 to Toolik does not include Lake I-8. The catchment:lake (C:L) area ratio is calculated using individual catchment and lake areas; note that the C:L for Toolik uses the entire catchment area (6688 ha) and not the area of the inlet series sub-basin (4660 ha)

\begin{tabular}{|c|c|c|c|c|c|c|c|c|c|}
\hline Lake name & $\begin{array}{l}\text { Lake chain } \\
\text { number }\end{array}$ & $\begin{array}{l}\text { Elevation } \\
\text { (m a.s.l.) }\end{array}$ & $\begin{array}{l}\text { Lake } \\
\text { area (ha) }\end{array}$ & $\begin{array}{l}\text { Maximum } \\
\text { depth }(\mathrm{m})\end{array}$ & $\begin{array}{l}\text { Volume } \\
\left(1000 \mathrm{~m}^{3}\right)\end{array}$ & $\begin{array}{l}\text { Catchment } \\
\text { area (ha) }\end{array}$ & $\begin{array}{l}\text { Cumulative } \\
\text { catchment } \\
\text { area (ha) }\end{array}$ & $\begin{array}{l}\text { C:L lake } \\
\text { area ratio }\end{array}$ & $\begin{array}{l}\text { WRT } \\
\text { (years) }\end{array}$ \\
\hline $\mathrm{I}-1$ & 1 & 785 & 18.2 & 10.4 & 710.5 & 106 & 106 & 5.8 & 4.3 \\
\hline $\mathrm{I}-2$ & 2 & 785 & 8.4 & 18 & 684.7 & 135 & 135 & 16.1 & 3.2 \\
\hline $\mathrm{I}-3$ & 3 & 774 & 3.2 & 4.9 & 55.4 & 95.3 & 336 & 29.6 & 0.4 \\
\hline $\mathrm{I}-4$ & 4 & 770 & 8.7 & 8 & 275.0 & 94.2 & 430 & 10.8 & 1.8 \\
\hline $\mathrm{I}-5$ & 5 & 767 & 18.1 & 8.4 & 678.8 & 186 & 616 & 10.3 & 2.3 \\
\hline I-6 & 6 & 754 & 16.7 & 15.8 & 1,014 & 325 & 942 & 19.4 & 2.0 \\
\hline $\mathrm{I}-7$ & 7 & 742 & 3.0 & 13.1 & 123.8 & 56.1 & 998 & 18.9 & 1.4 \\
\hline $\mathrm{I}-8$ & & 744 & 16.3 & 9.1 & 486.4 & 2928 & & 179 & 0.1 \\
\hline I-Swamp & 8 & 736 & 1.9 & 5.5 & 34.6 & 86.9 & 1085 & 46.0 & 0.3 \\
\hline Toolik & 9 & 719 & 149 & 25 & 10,566 & 6688 & 4660 & 44.9 & 1.0 \\
\hline \multicolumn{10}{|l|}{ Stream site } \\
\hline I-8-Headwater & & 808 & & & & & & & \\
\hline Milky Way & & 725 & & & & & & & \\
\hline I-9 & & 728 & & & & & & & \\
\hline
\end{tabular}

(c) 2000 Blackwell Science Ltd, Freshwater Biology, 43, 477-497 
absolute difference $=1.6 \%$, range $=-10.0$ to $+9.6 \%$ for individual variables). The very few comparisons of particulate materials (e.g. chl $a$ ) showed that the outlet samples tended to have lower concentrations than samples collected from the middle of the lake.

Temperature was measured using a calibrated glass thermometer or an Orion conductivity meter (Orion, Boston, MA); $\mathrm{pH}$ was measured using an Orion meter and a triode or Ross electrode (Orion, Boston, MA); conductivity was measured using an Orion meter; underwater irradiance was measured using a Licor meter (Licor, Lincoln, NE) and $2 \pi$ sensor; and oxygen was measured using a YSI meter (Licor, Lincoln, NE) calibrated against Winkler titrations.

Water samples for most analyses were filtered in the field through pre-combusted Whatman GF/F (Whatman, Clifton, NJ) glass fibre filters or GF/C filters (Whatman, Clifton, NJ) for chlorophyll determination. Alkalinity (ALK) was measured using potentiometric titrations and analysed with the Gran method. Dissolved organic carbon (DOC) samples were acidified in the field with trace-metal grade acid to $\mathrm{pH} \approx 3$, and stored in a cool and dark place until analysis using a high-temperature platinum-catalysed combustion followed by infrared detection of $\mathrm{CO}_{2}$ (Shimadzu TOC-5000; Shimadzu, Columbia, MD); replicate analyses of single field samples processed on different machine operating days deviated by $5.4 \%$ on average (absolute values of $n=576$ comparisons). Dissolved $\mathrm{CO}_{2}$ and $\mathrm{CH}_{4}$ were measured using a headspace equilibration with sample water and ambient air in the field with $60-\mathrm{mL}$ plastic syringes. The headspace gas was transferred to 20-mL nylon syringes fitted with Viton O-rings to reduce sample leakage and was analysed the same day on a gas chromatograph. Partial pressures and dissolved concentrations of $\mathrm{CO}_{2}$ and $\mathrm{CH}_{4}$ were calculated following the procedure of Kling, Kipphut \& Miller (1992b). Samples for dissolved inorganic carbon (DIC) were collected in the field by overfilling 20-mL glass bottles until the water was bubble free, adding $20 \mu \mathrm{L}$ of saturated $\mathrm{HgCl}_{2}$, and crimping the bottle closed with a Teflon seal and aluminium cap. The samples were acidified in the laboratory to convert all carbonate species to $\mathrm{CO}_{2}$ and a headspace equilibration was performed as described above. Final concentrations of DIC were calculated following the methods of Kling et al. (1992b). Nutrients [i.e. soluble reactive phosphorus (SRP), $\mathrm{NH}_{4}^{+}$and $\mathrm{NO}_{3}{ }^{-}$) were measured spectrophotometrically on a Technicon II or Alpkem autoanalyser (Alpkem, College Station, TX) or by hand, usually within $24 \mathrm{~h}$ (methods followed the Arctic-LTER protocols, found at www.mbl.edu/ html/ECOSYSTEMS/lterhtml/arc.html). Total dissolved nitrogen (TDN) was measured on an autoanalyser after a potassium persulphate digestion (modified from Langner \& Hendrix, 1982). Major cations (i.e. $\mathrm{Ca}^{2+}, \mathrm{Mg}^{2+}, \mathrm{Na}^{+}$and $\mathrm{K}^{+}$) were analysed on a Perkin Elmer (Perkin Elmer, Norwalk, CT) atomic absorption spectrophotometer and major anions (i.e. $\mathrm{Cl}^{-}$and $\mathrm{SO}_{4}{ }^{2-}$ were analysed on a Dionex (Dionex, Sunnyvale, CA) Ion Chromatograph. The mean value $( \pm \mathrm{SE})$ of the absolute deviation from cation-anion balance was $7.9 \pm 0.6 \% ; n=217$ ), and there was no particular trend of anion or cation excess.

Particulate carbon (PC) and nitrogen (PN) were measured on a Perkin Elmer CHN analyser. Particulate phosphorus (PP) was measured using a $\mathrm{HCl}$ digestion followed by analysis of SRP on an autoanalyser. Chlorophyll $a(\mathrm{Chl} a)$ was measured spectrophotometrically following a 24-h extraction with $90 \%$ methanol in the dark. Primary productivity was measured using a ${ }^{14} \mathrm{C}$ method, as described in Miller et al. (1986).

\section{Statistical analyses}

Changes in chemical and biological variables caused by internal processing in lakes and streams were calculated by comparing the lake outlet to inlet values, and the values at the upstream and downstream ends of stream segments. These difference calculations were made for lakes I-3, I-4, I-5, I-6, I-7 and I-8, and for the stream segments between lakes I- 1 and I-3, I-2 and I-3, I-4 and I-5, I-5 and I-6, I-7 and I-Swamp, ISwamp and I-9, I-8 and I-9, I-9 and Toolik, and between I-8 Headwaters and Lake I-8 (see Fig. 1).

All variables for statistical analyses were transformed to correct for deviations from normal distributions or were analysed using non-parametric tests. Spatial patterns and the degree to which variables or lake pairs behaved similarly over time (i.e. 'temporal coherence' or 'synchrony') were analysed by graphing, or by determining either the correlation among all lake pairs for specific variables or the correlation between specific lake pairs across all variables. Synchrony values were calculated across all 
years of data for all lakes; no analysis of synchrony over specific seasons or years was performed. Both Pearson and Spearman correlations were calculated and were very similar with no obvious biases in the residuals [Spearman's rho $=(0.98 \times$ Pearson's $r)-$ $0.02 ; r^{2}=0.86$ for the comparison of all variables across the forty-five possible lake pairs]. We used the Pearson correlations for this study and determined the number of 'strong' correlations between lake pairs, which included all correlations which had statistical values of $P<0.05$.

We tested the null model that all synchrony estimates were centred on a mean of zero (i.e. random and equal positive and negative synchrony), and found that the average correlation among all lake and variable combinations was significantly greater than zero at the $P<0.001$ level. The mean Pearson correlations of all variables among all lake pairs were plotted against the rank order of each lake pair. The rank order for any variable, such as altitude, spatial proximity or lake volume, was calculated using the morphometric data in Table 1. For example, in the calculation of spatial proximity for each lake pair, a ranking was assigned as ' 1 ' if the two lakes were closest to each other in straight-line distance, ' 2 ' if the pair was separated by one other lake and so on until the highest rank was assigned to lake pairs which were most dissimilar in proximity; thus, the rank order of proximity is really the difference in lake chain number between two lakes.

\section{Results}

The statistical summaries for the eighteen chemical and biological variables measured in the lakes and streams are presented in Tables 2 and 3. These lakes contain low-conductivity waters which are dominated by carbonate alkalinity and calcium as the major ions. For cations, the ranking of dominance in mean concentration in every lake was $\mathrm{Ca}^{2+}>\mathrm{Mg}^{2+}$ $>\mathrm{Na}^{+}>\mathrm{K}^{+}$, and for anions, the concentrations of $\mathrm{SO}_{4}{ }^{2-}$ or $\mathrm{Cl}^{-}$were always less than $5 \%$ of the concentration of bicarbonate (Table 4). On average, the lakes have circumneutral $\mathrm{pH}$ values. The lakes

Table 2 Statistical description of chemical and biological variables for all lake sites across all years (ten lakes): (SE) standard error of the mean; and $(\mathrm{CV} \%)$ is the coefficient of variation

\begin{tabular}{|c|c|c|c|c|c|c|}
\hline Variable & Number & Mean & Minimum & Maximum & SE & $\mathrm{CV} \%$ \\
\hline $\operatorname{COND}\left(\mu \mathrm{S} \mathrm{cm}^{-1}\right)$ & 265 & 36.4 & 10 & 74 & 0.9 & 38.6 \\
\hline $\mathrm{pH}$ & 277 & 7.36 & 5.56 & 8.60 & 0.03 & 6.2 \\
\hline $\operatorname{ALK}\left(\mu \mathrm{eq} \mathrm{L}{ }^{-1}\right)$ & 253 & 324 & 67 & 663 & 8.8 & 43.2 \\
\hline DIC $(\mu \mathrm{M})$ & 113 & 324 & 155 & 539 & 11.0 & 36.1 \\
\hline DOC $(\mu \mathrm{M})$ & 207 & 497 & 166 & 1128 & 7.8 & 22.5 \\
\hline $\mathrm{CO}_{2}(\mu \mathrm{M})$ & 179 & 43.4 & 18.6 & 463 & 2.9 & 89.0 \\
\hline $\mathrm{CH}_{4}(\mu \mathrm{M})$ & 179 & 0.415 & 0.002 & 2.43 & 0.03 & 104 \\
\hline $\mathrm{NH}_{4}^{+}(\mu \mathrm{M})$ & 223 & 0.79 & 0.01 & 3.7 & 0.05 & 98.4 \\
\hline $\mathrm{NO}_{3}^{-}(\mu \mathrm{M})$ & 215 & 0.17 & 0.01 & 1.29 & 0.02 & 136 \\
\hline SRP $(\mu \mathrm{M})$ & 221 & 0.08 & 0.01 & 0.34 & 0.004 & 87.4 \\
\hline TDN $(\mu \mathrm{M})$ & 94 & 19.3 & 7.70 & 79.3 & 1.44 & 72.4 \\
\hline $\mathrm{PC}(\mu \mathrm{M})$ & 143 & 30.7 & 8.4 & 148 & 1.59 & 61.9 \\
\hline $\mathrm{PN}(\mu \mathrm{M})$ & 141 & 2.47 & 0.14 & 17.2 & 0.17 & 82.9 \\
\hline $\mathrm{PP}(\mu \mathrm{M})$ & 107 & 0.11 & 0.01 & 1.89 & 0.02 & 177 \\
\hline $\mathrm{Chl} a\left(\mu \mathrm{g} \mathrm{L}^{-1}\right)$ & 222 & 1.02 & 0.05 & 4.69 & 0.06 & 84.3 \\
\hline $1^{\circ} \operatorname{Prod}\left(\mu \mathrm{mol} \mathrm{C} \mathrm{L}{ }^{-1} \mathrm{day}^{-1}\right)$ & 37 & 3.23 & 0.16 & 19.2 & 0.64 & 121 \\
\hline $\mathrm{Ca}^{2+}(\mu \mathrm{M})$ & 138 & 136 & 52.4 & 358 & 5.3 & 45.6 \\
\hline $\mathrm{Mg}^{2+}(\mu \mathrm{M})$ & 164 & 30.2 & 14.0 & 70.8 & 0.9 & 38.3 \\
\hline $\mathrm{Na}^{+}(\mu \mathrm{M})$ & 163 & 13.8 & 4.4 & 30.0 & 0.5 & 42.8 \\
\hline $\mathrm{K}^{3+}(\mu \mathrm{M})$ & 165 & 7.3 & 1.3 & 11.5 & 0.17 & 29.8 \\
\hline $\mathrm{Cl}^{-}(\mu \mathrm{M})$ & 105 & 5.2 & 1.2 & 25.9 & 0.4 & 87.7 \\
\hline $\mathrm{SO}_{4}^{2-}(\mu \mathrm{M})$ & 132 & 4.4 & 0.2 & 21.0 & 0.3 & 74.8 \\
\hline $\mathrm{Si}(\mu \mathrm{M})$ & 7 & 17.2 & 11.2 & 32.3 & 2.8 & 42.4 \\
\hline Secchi disk (m) & 99 & 4.1 & 2.0 & 6.7 & 0.10 & 23.6 \\
\hline
\end{tabular}

(c) 2000 Blackwell Science Ltd, Freshwater Biology, 43, 477-497 
Table 3 Statistical description of the chemical and biological variables for all stream sites across all years (thirteen non-lake sites, see Fig. 1): (S/L\%) average difference in percentage between the values for stream sites and the values for lake sites (positive value indicates that stream sites had a higher mean value than the lake sites); (SE) standard error of the mean; and (CV\%) is the coefficient of variation. The $P$-value indicates the statistical significance of a Wilcoxon test on differences in mean values between lake and stream sites

\begin{tabular}{|c|c|c|c|c|c|c|c|c|}
\hline Variable & Number & Mean & Minimum & Maximum & SE & $\mathrm{CV} \%$ & S/L\% & $P$-value \\
\hline $\operatorname{COND}\left(\mu \mathrm{S} \mathrm{cm}{ }^{-1}\right)$ & 470 & 52.9 & 12 & 160 & 1.24 & 50.8 & 31.3 & $<0.01$ \\
\hline $\mathrm{pH}$ & 464 & 7.32 & 5.88 & 10.1 & 0.02 & 6.71 & -0.6 & $<0.01$ \\
\hline $\operatorname{ALK}\left(\mu \mathrm{eq} \mathrm{L}^{-1}\right)$ & 377 & 485 & 37.6 & 1558 & 14.2 & 56.8 & 33.1 & $<0.01$ \\
\hline $\mathrm{DIC}(\mu \mathrm{M})$ & 307 & 447 & 160 & 1259 & 11.2 & 43.9 & 27.5 & $<0.01$ \\
\hline DOC $(\mu \mathrm{M})$ & 447 & 490 & 252 & 1122 & 5.58 & 24.1 & -1.4 & - \\
\hline $\mathrm{CO}_{2}(\mu \mathrm{M})$ & 428 & 57.8 & 0.15 & 357 & 1.33 & 47.5 & 28.5 & $<0.01$ \\
\hline $\mathrm{CH}_{4}(\mu \mathrm{M})$ & 427 & 0.36 & 0.002 & 17.2 & 0.05 & 271 & -16.3 & $<0.01$ \\
\hline $\mathrm{NH}_{4}{ }^{+}(\mu \mathrm{M})$ & 388 & 0.72 & 0.01 & 4.12 & 0.04 & 98.3 & -10.2 & $<0.01$ \\
\hline $\mathrm{NO}_{3}^{-}(\mu \mathrm{M})$ & 359 & 0.8 & 0.01 & 7.41 & 0.06 & 154 & 78.8 & $<0.01$ \\
\hline $\operatorname{SRP}(\mu \mathrm{M})$ & 399 & 0.12 & 0.01 & 0.88 & 0.006 & 102 & 35.3 & - \\
\hline TDN $(\mu \mathrm{M})$ & 165 & 18.4 & 6.95 & 117 & 1.03 & 71.8 & -4.8 & $<0.01$ \\
\hline PC $(\mu \mathrm{M})$ & 352 & 24.4 & 3.41 & 227 & 1.27 & 97.8 & -25.9 & $<0.05$ \\
\hline $\mathrm{PN}(\mu \mathrm{M})$ & 348 & 1.86 & 0.10 & 18.3 & 0.11 & 106 & -32.7 & - \\
\hline $\mathrm{PP}(\mu \mathrm{M})$ & 112 & 0.08 & 0.01 & 1.68 & 0.02 & 211 & -46.7 & - \\
\hline Chl $a\left(\mu \mathrm{g} / \mathrm{L}^{-1}\right)$ & 193 & 0.53 & 0.02 & 7.33 & 0.05 & 132 & -92.5 & $<0.05$ \\
\hline $\mathrm{Ca}^{2+}(\mu \mathrm{M})$ & 171 & 188 & 57.4 & 649 & 8.59 & 59.6 & 28.0 & $<0.01$ \\
\hline $\mathrm{Mg}^{2+}(\mu \mathrm{M})$ & 243 & 45.4 & 15.2 & 113 & 1.4 & 48.1 & 33.6 & $<0.01$ \\
\hline $\mathrm{Na}^{+}(\mu \mathrm{M})$ & 238 & 15.6 & 5.66 & 49.2 & 0.5 & 49.5 & 11.6 & - \\
\hline $\mathrm{K}^{+}(\mu \mathrm{M})$ & 243 & 5.37 & 0.01 & 11 & 0.15 & 42.4 & -35.5 & $<0.01$ \\
\hline $\mathrm{Cl}^{-}(\mu \mathrm{M})$ & 150 & 5.86 & 0.71 & 63.2 & 0.65 & 136 & 10.6 & - \\
\hline $\mathrm{SO}_{4}{ }^{2-}(\mu \mathrm{M})$ & 182 & 5.42 & 0.31 & 59.6 & 0.42 & 106 & 18.4 & - \\
\hline $\mathrm{Si}(\mu \mathrm{M})$ & 55 & 29.4 & 13.6 & 49.6 & 1.16 & 29.4 & 41.3 & - \\
\hline
\end{tabular}

are relatively stained and the mean DOC concentration for all lakes was $497 \mu \mathrm{M}$ C. Light penetration as measured by Secchi depth was $4.1 \mathrm{~m}$ on average. Nutrient concentrations were very low in these arctic lakes, and values of $\mathrm{NH}_{4}{ }^{+}, \mathrm{NO}_{3}{ }^{-}$and SRP were often below detection. Consequently, the overall productivity of lakes in the Toolik area is very low ( $\approx 10 \mathrm{~g} \mathrm{C} \mathrm{m}^{-2}$ year $^{-1}$, see Miller et al., 1986) and the mean chl $a$ concentration for all study lakes was only $1.02 \mu \mathrm{g} \mathrm{L}^{-1}$.

A comparison between the average values for lakes and the average values for streams shows that the stream sites tended to have higher values of major anions and cations (except for $\mathrm{K}^{+}$) than the lake sites, while the lake sites had higher values (but not always significantly different) of particulate C, N, P and chl $a$ (Table 3). There is also a pattern between streams and lakes for variables related to redox conditions; the more open and oxidized streams have higher concentrations than the lakes of $\mathrm{CO}_{2}$ relative to $\mathrm{CH}_{4}$ and of $\mathrm{NO}_{3}{ }^{-}$relative to $\mathrm{NH}_{4}{ }^{+}$. We found that all lakes and streams had pressures of dissolved $\mathrm{CO}_{2}$ (mean $=775$ and $1083 \mu \mathrm{atm}$, respectively) and $\mathrm{CH}_{4}$ (mean $=223$ and $168 \mu \mathrm{atm}$, respectively) which were significantly higher than atmospheric pressures; this supersaturation is consistent with previous findings (Kling, Kipphut \& Miller, 1991; 1992b). Finally, the variability in both lakes and streams expressed as the coefficient of variation $(\mathrm{CV}, \%)$ ranged from a low of $6.2 \%$ for lake $\mathrm{pH}$ to a high of $271 \%$ for stream $\mathrm{CH}_{4}$. The highest $\mathrm{CVs}$ were found in variables strongly altered by biological processes, such as chl $a$, nutrients and dissolved methane. Major ions (except for $\mathrm{Cl}^{-}$) and $\mathrm{pH}$ tended to be much less variable.

The mean values of all variables for each individual lake and stream site are given in Table 4 . The highest concentrations of all major ions, $\mathrm{NO}_{3}{ }^{-}$and SRP are found in the Milky Way stream (series number 21). This stream flows through an old gravel pad, as noted above, and the effect of this landscape disturbance on stream water chemistry is clearly seen by comparing the much lower ion concentrations found in this 


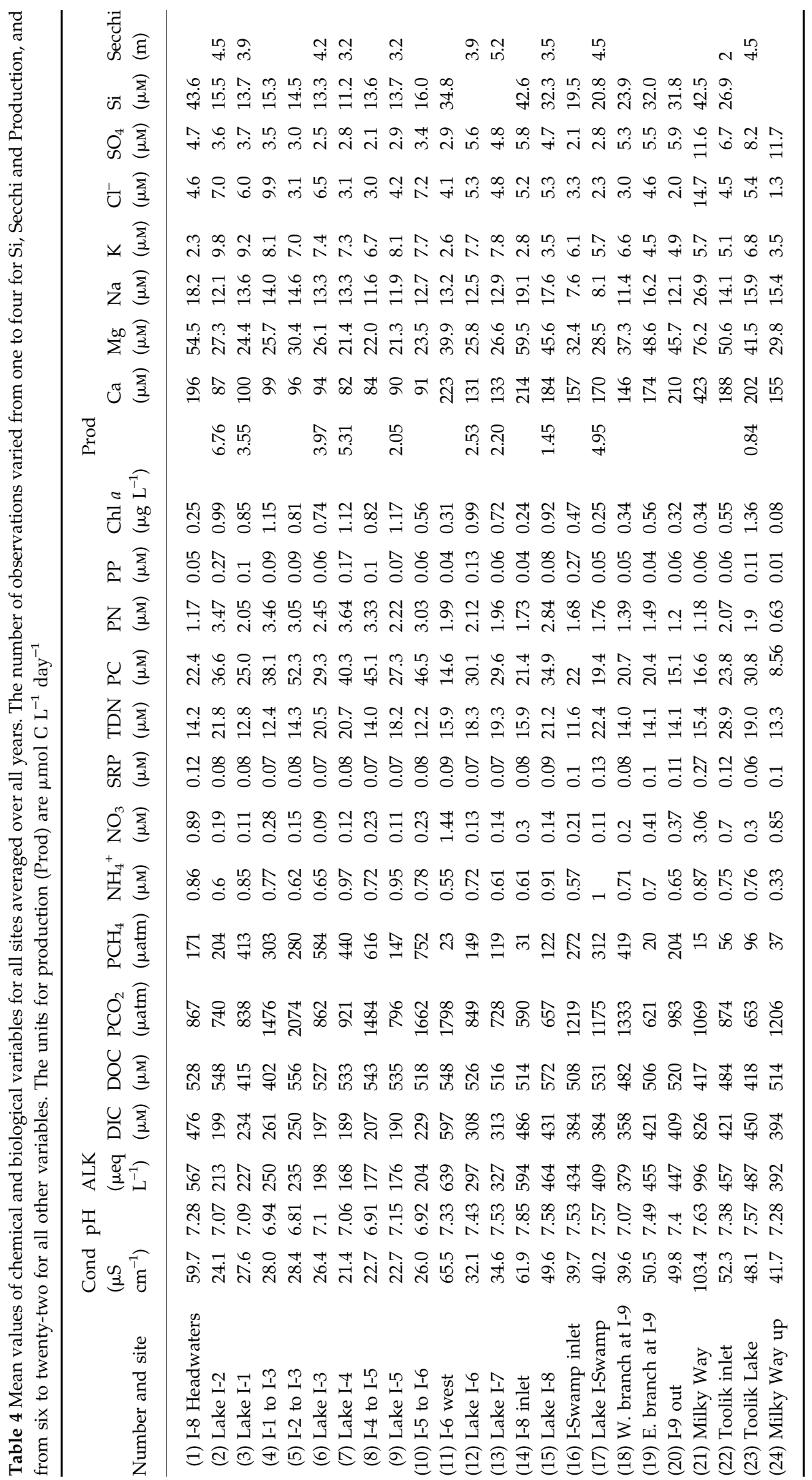



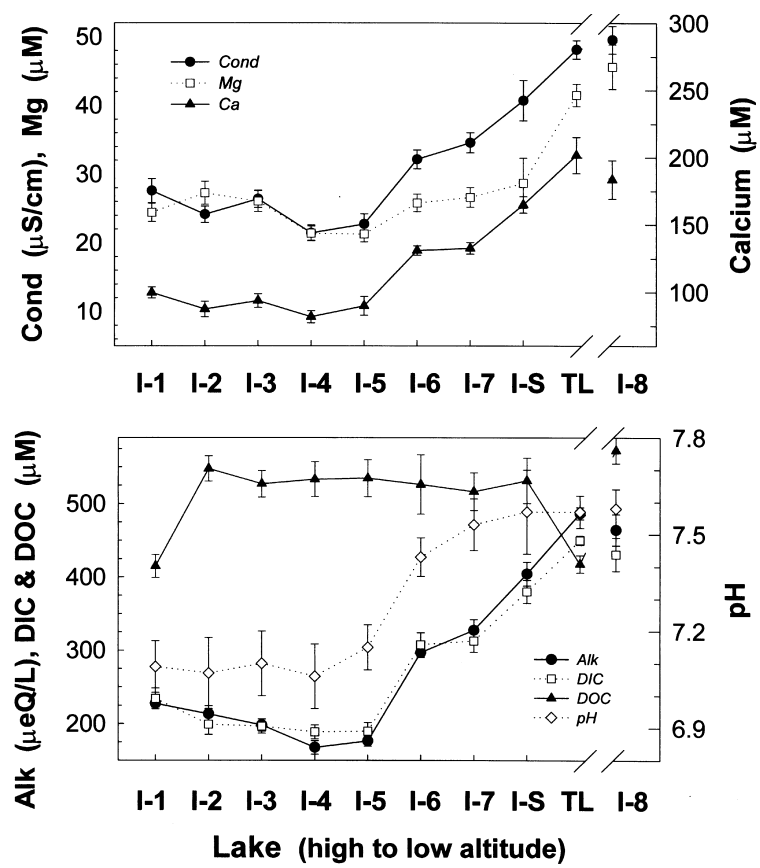

Fig. 2 Mean values of chemical variables plotted along the series of lakes from the headwaters down in altitude to Toolik Lake (TL); note that I-1 and I-2 are headwater lakes at the same altitude. Lake I-8 is at the same altitude as Lake I-7, but is not connected in the chain of lakes starting at I-1 and I-2 (see Fig. 1), and therefore, $\mathrm{I}-8$ is plotted at the far right in this figure. The error bars represent the standard error (SE) of the mean.

stream before it reaches the gravel pad (Milky Way upper, series number 24) to the higher concentrations in Milky Way when it enters the Toolik Inlet stream. Such anthropogenic disturbances are rare and highly localized in the Toolik basin, and probably do not influence the major patterns in water chemistry found in this study.

\section{Spatial patterns}

The observed spatial patterns in the study lakes included variables whose mean values increased, decreased or did not change along the lake chain from high to low altitude in the catchment (Figs $2 \& 3$ ). There were no distinct spatial patterns for any stream sites. Most variables showed no statistically significant relationship with lake chain number, similar to the lack of pattern shown for DOC in Fig. 2. The strongest spatial patterns were of increasing conductivity, $\mathrm{Ca}^{2+}$, $\mathrm{Mg}^{2+}$, alkalinity, DIC and $\mathrm{pH}$ with lake chain number (Fig. 2). There were only two sets of variables which showed a slight tendency to decrease with lake chain number: (1) primary productivity; and (2) the particulate concentrations of $\mathrm{C}, \mathrm{N}$ and $\mathrm{P}$ (Fig. 3).

In addition to these patterns across the drainage basin, there were consistent patterns in the processing of materials flowing through the streams connecting the lakes and in the lakes themselves. Over all years, the data in Table 5 indicate that, on average, the lakes tended to 'consume' statistically significant amounts of $\mathrm{CO}_{2}, \mathrm{CH}_{4}$, alkalinity, $\mathrm{DIC}, \mathrm{Ca}^{2+}, \mathrm{Mg}^{2+}$ and $\mathrm{NO}_{3}{ }^{-}$as water flowed through them. At the same time, the stream segments tended to 'produce' those same solutes in relatively similar amounts. For example, there was an average net loss or consumption of $377 \mu \mathrm{atm}$ of $\mathrm{CO}_{2}$ pressure in the lakes, while the stream segments on average gained or produced $342 \mu$ atm of $\mathrm{CO}_{2}$ (Table 5).

\section{Synchrony}

Synchrony of variables across all lakes ranged from 0.18 for PP to 0.90 for $\mathrm{Mg}^{2+}$ and from $11 \%$ to $100 \%$
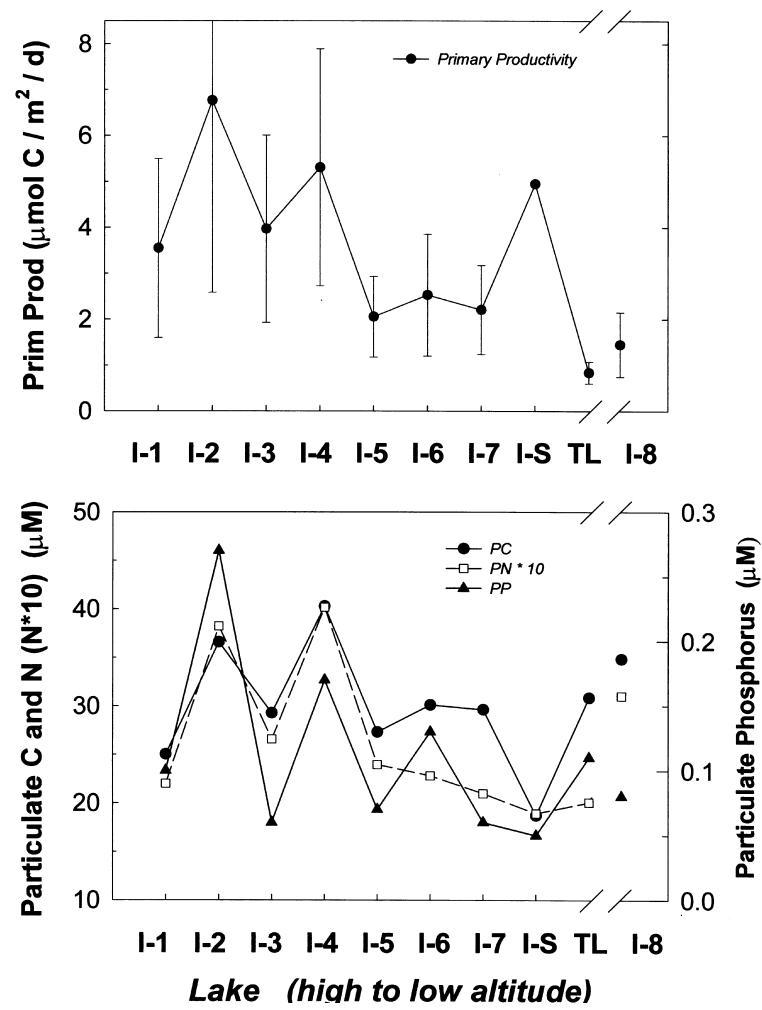

Fig. 3 Mean values of biological variables plotted along the series of lakes from the headwaters down in altitude to Toolik Lake (same as in Fig. 2). Plotted values of particulate nitrogen $(\mathrm{PN})$ have been multiplied by ten to fit on the graph. The error bars represent the standard error (SE) of the mean. 
Table 5 Effects of lake and stream processing by variable for all sites. The mean values ( \pm SE) are calculated for lakes by subtracting the inlet values from the outlet values and for streams by subtracting the upstream values (at the lake outlet) from the downstream values (at the inlet of the next lake). Positive values indicate production of materials and negative values indicate consumption either in the lake or in the stream reach between adjacent lakes in the chain. Variables are sorted by decreasing consumption in lakes; (N) number of individual difference comparisons. The $P$-value indicates the significance level of a $t$-test (unequal variances) in which the mean value is significantly different from zero

\begin{tabular}{|c|c|c|c|c|c|c|c|c|}
\hline \multirow[b]{2}{*}{ Variable } & \multicolumn{4}{|c|}{ Lakes (out-in) } & \multicolumn{4}{|c|}{ Streams (down-up) } \\
\hline & Mean & SE & $\mathrm{N}$ & $P$-value & Mean & SE & $\mathrm{N}$ & $P$-value \\
\hline $\mathrm{PCO}_{2}$ ( $\left.\mu \mathrm{atm}\right)$ & -377 & 61 & 86 & $<0.01$ & 342 & 61 & 141 & $<0.01$ \\
\hline $\mathrm{PCH}_{4}(\mu \mathrm{atm})$ & -96 & 40 & 86 & $<0.01$ & 36 & 29 & 141 & - \\
\hline $\operatorname{ALK}\left(\mu\right.$ eq $\left.L^{-1}\right)$ & -40 & 9.9 & 102 & $<0.01$ & 34 & 7.4 & 140 & $<0.01$ \\
\hline $\mathrm{DIC}(\mu \mathrm{M})$ & -24 & 6.4 & 50 & $<0.01$ & 30 & 3.1 & 98 & $<0.01$ \\
\hline $\mathrm{Ca}^{2+}(\mu \mathrm{M})$ & -11 & 4.3 & 69 & $<0.01$ & 9.4 & 2.6 & 78 & $<0.01$ \\
\hline $\mathrm{PC}(\mu \mathrm{M})$ & -5.0 & 3.3 & 79 & - & 6.5 & 3.2 & 123 & $<0.05$ \\
\hline $\mathrm{Mg}^{2+}(\mu \mathrm{M})$ & -3.7 & 0.98 & 85 & $<0.01$ & 3.0 & 0.80 & 102 & $<0.01$ \\
\hline Cond $\left(\mu S \mathrm{~cm}^{-1}\right)$ & -3.7 & 0.92 & 112 & $<0.01$ & 2.5 & 0.45 & 164 & $<0.01$ \\
\hline $\mathrm{Cl}^{-}(\mu \mathrm{M})$ & -1.1 & 1.5 & 56 & - & 1.2 & 1.1 & 67 & - \\
\hline TDN $(\mu \mathrm{M})$ & -1.0 & 3.3 & 36 & - & 3.5 & 1.7 & 60 & $<0.05$ \\
\hline $\mathrm{PN}(\mu \mathrm{M})$ & -0.26 & 0.28 & 76 & - & 0.21 & 0.29 & 119 & - \\
\hline $\mathrm{Na}^{+}(\mu \mathrm{M})$ & -0.10 & 0.39 & 85 & - & 0.56 & 0.38 & 101 & - \\
\hline $\mathrm{NO}_{3}^{-}(\mu \mathrm{M})$ & -0.10 & 0.02 & 83 & $<0.01$ & 0.05 & 0.03 & 117 & - \\
\hline $\operatorname{SRP}(\mu \mathrm{M})$ & -0.00 & 0.00 & 93 & - & -0.00 & 0.01 & 132 & - \\
\hline $\mathrm{PP}(\mu \mathrm{M})$ & 0.02 & 0.02 & 42 & - & -0.02 & 0.04 & 66 & - \\
\hline $\mathrm{pH}$ & 0.11 & 0.03 & 112 & $<0.01$ & 0.01 & 0.03 & 162 & - \\
\hline $\mathrm{NH}_{4}^{+}(\mu \mathrm{M})$ & 0.11 & 0.04 & 88 & $<0.01$ & -0.13 & 0.05 & 131 & $<0.01$ \\
\hline $\mathrm{SO}_{4}^{2-}(\mu \mathrm{M})$ & 0.13 & 0.42 & 75 & - & 0.07 & 0.21 & 82 & - \\
\hline Chl $a\left(\mu \mathrm{g} \mathrm{L}^{-1}\right)$ & 0.17 & 0.08 & 93 & $<0.05$ & -0.11 & 0.08 & 113 & - \\
\hline $\mathrm{K}^{+}(\mu \mathrm{M})$ & 0.50 & 0.14 & 85 & $<0.01$ & -0.59 & 0.15 & 102 & $<0.01$ \\
\hline DOC $(\mu \mathrm{M})$ & 14 & 11 & 102 & - & -6.9 & 5.6 & 151 & - \\
\hline
\end{tabular}

strong correlations, respectively (Table 6). The average synchrony for all twenty-one variables was 0.50 and the average number of strong correlations was $42 \%$. These average values are taken across all lake pairs and may hide spatial patterns in synchrony. For example, when the synchrony of $\mathrm{Ca}^{2+}$ is shown with each separate lake pair (Table 7), it is clear that lakes close to one another have strong positive synchrony and lakes separated by great distances have strong negative synchrony; the result is a low average synchrony of 0.27 .

When all variables are combined, the average tendencies of synchrony for various lake pairs can be estimated. The mean synchrony of all variables across all lake pairs was 0.50 and the average number of strong correlations was $51 \%$. The variables were also divided into two groups representing the more conservative 'major ions', and the less conservative 'nutrient' variables including dissolved and particu- late $\mathrm{N}$ and $\mathrm{P}, \mathrm{chl} a, \mathrm{DOC}$, and dissolved gases. The average synchrony values for these groups across lake pairs are shown in Table 9. The overall average synchrony for the major ions was 0.48 , and for the nutrients, it was 0.52 . In almost all cases, and similar to other studies (Magnuson et al., 1990; Soranno et al., 1999), high values of synchrony between lake pairs corresponded with high percentages of strong correlations (data not shown).

In the analysis of spatial patterns, a principal assumption is that the behaviour or response of objects such as lakes which are physically close to one another is more correlated than the response of objects separated by greater distances. Robust determination of the spatial scale at which this autocorrelation is important (semi-variogram analysis) requires a minimum of between 20 and 30 sample points (Legendre \& Fortin, 1989; Levin et al., 1993); this analysis was not performed for our data set because of 
Table 6 Average synchrony values as determined by Pearson correlations for each variable across all lake pairs. The percentage of correlations which were statistically significant at the $P<0.05$ level is also shown

\begin{tabular}{llll}
\hline Variable & Synchrony & $\begin{array}{l}\text { Strong } \\
\text { correlations (\%) }\end{array}$ & Type \\
\hline $\mathrm{Mg}^{2+}$ & 0.90 & 100 & Major ion \\
$\mathrm{NH}_{4^{+}}$ & 0.75 & 87 & Nutrient \\
$\mathrm{Na}^{+}$ & 0.74 & 73 & Nutrient \\
$\mathrm{TDN}$ & 0.73 & 80 & Major ion \\
$\mathrm{SRP}$ & 0.70 & 71 & Nutrient \\
$\mathrm{Chl} a$ & 0.70 & 89 & Major ion \\
$\mathrm{NO}_{3}{ }^{-}$ & 0.65 & 70 & Nutrient \\
$\mathrm{CO}_{2}$ & 0.60 & 67 & Nutrient \\
$\mathrm{DIC}$ & 0.52 & 40 & Major ion \\
$\mathrm{K}^{+}$ & 0.48 & 47 & Nutrient \\
$\mathrm{pH}$ & 0.45 & 51 & Major ion \\
$\mathrm{Cond}$ & 0.44 & 47 & Major ion \\
$\mathrm{SO}_{4}{ }^{2-}$ & 0.40 & 52 & Nutrient \\
$\mathrm{CH}$ & 0.39 & 22 & Major ion \\
$\mathrm{PC}^{+}$ & 0.38 & 22 & Major ion \\
$\mathrm{ALK}$ & 0.35 & 36 & Major ion \\
$\mathrm{DOC}$ & 0.35 & 40 & Major ion \\
$\mathrm{PN}_{\mathrm{Ca}}^{2+}$ & 0.32 & 22 & Nutrient \\
$\mathrm{Cl}^{-}$ & 0.27 & 34 & Major ion \\
$\mathrm{PP}^{-}$ & 0.24 & 23 & Major ion \\
\hline & 0.18 & 11 & Nutrient \\
\hline & & &
\end{tabular}

the small sample size of ten lakes. We did estimate the overall strength of spatial autocorrelation by correlating the rank order of proximity or morphological measures of the lake pairs against the mean synchrony values of chemical and biological variables for all lake pairs (Table 10). The synchrony of the variables measured was most strongly related to the spatial position of the lakes (their proximity to one another), and secondarily to the catchment to lake area ratio (C:L) and WRT (shown in Table 10). Not shown are three negative correlations significant at the $P=0.05$ level for which we have no mechanistic interpretation: $\mathrm{pH}$ and $\mathrm{Na}^{+}$with catchment area, $\mathrm{Mg}^{2+}$ with lake area, and $\mathrm{CO}_{2}$ with mean depth.

\section{Discussion}

Spatial patterns in lake variables

Large-scale spatial gradients in lake variables can be caused by the presence of strongly 'regionalized' environmental variables, such as a climatic shift or change from one geologic substrate to another across the area of study. The Toolik inlet basin is too small to be exposed to a substantial gradient of climate, but two main geologic substrates do exist: an older landscape covers much of the hills and highlands of the basin, while the valleys which contain the lakes are filled with younger outwash materials from a more recent glaciation. The chemistry of arctic surface waters, away from the coast and the influence of sea salts, is controlled mainly by differences in geological substrate and the age of the landscape (time since last glacial cover). For example, lakes found on recently glaciated soils contain water of higher ionic strength and different ion ratios than do lakes on landscapes which were glaciated more distantly in the past (Kling et al., 1992a). Compared to these previous data, the lakes and streams in this study had nearly identical molar ratios of $\mathrm{Ca}: \mathrm{Cl}, \mathrm{Mg}: \mathrm{Cl}, \mathrm{Na}: \mathrm{Cl}$ and $\mathrm{HCO}_{3}: \mathrm{Cl}$ to the ratios in lakes found on older glacial till, rather than to the much higher ratios found in lakes on newer glacial till (ratios presented in Kling et al., 1992a). This indicates that the older landscape covering much of the Toolik inlet basin dominates in its contribution to water chemistry over the younger substrate found in the valleys. Therefore, major regionalized variables do not appear to exist within the Toolik inlet basin, and the observed spatial patterns in solute and particulate chemistry must be related to other factors.

The strongest spatial patterns were of increasing solute concentrations moving down the lake chain (Fig. 2); similar patterns have been observed in several other studies (Swanson et al., 1988; Magnuson et al., 1990; Kratz et al., 1997; Soranno et al., 1999). From a mass balance standpoint, the interpretation of these patterns is one of simple accumulation of solutes moving downslope. The accumulation results from

Table 7 Synchrony values for individual lake pair comparisons with Lake I-1

\begin{tabular}{ll}
\hline Lake & Synchrony for $\mathrm{Ca}^{2+}$ \\
\hline I-2 & 0.93 \\
I-3 & 0.92 \\
I-4 & 0.91 \\
I-5 & 0.50 \\
I-6 & 0.12 \\
I-7 & 0.16 \\
I-8 & -0.02 \\
I-Swamp & -0.50 \\
Toolik & -0.94 \\
\hline
\end{tabular}

(C) 2000 Blackwell Science Ltd, Freshwater Biology, 43, 477-497 
Table 8 Changes in concentrations weathering variables as a result of processing in lakes and stream segments. Region 1 includes lakes I-3, I-4 and I-5, and the all stream segments in between lakes I-1 and I-6. Region 2 includes sites lower in the basin, lakes I-6 and I7, and all stream segments between Lake I-6 and Toolik Lake. P-values are shown for a non-parametric Wilcoxon test of the null hypothesis that the mean values are different between regions; (NS) not significant

\begin{tabular}{|c|c|c|c|c|c|c|}
\hline \multirow[b]{2}{*}{ Variable } & \multicolumn{3}{|l|}{ Lakes } & \multicolumn{3}{|l|}{ Streams } \\
\hline & Region 1 & Region 2 & $P$-value & Region 1 & Region 2 & $P$-value \\
\hline Alk $\left(\mu \mathrm{eq} \mathrm{L}^{-1}\right)$ & -27 & -1.8 & $<0.01$ & 27 & 46 & 0.03 \\
\hline $\mathrm{Ca}_{2}^{+}(\mu \mathrm{M})$ & -5.4 & 1.2 & 0.07 & 4.0 & 13 & 0.02 \\
\hline $\mathrm{Mg}^{2+}(\mu \mathrm{M})$ & -2.4 & -0.6 & $<0.01$ & 1.8 & 4.5 & 0.02 \\
\hline $\mathrm{pH}$ & 0.15 & 0.19 & NS & -0.20 & 0.07 & $<0.01$ \\
\hline $\mathrm{PCH}_{4}$ ( $\left.\mu \mathrm{atm}\right)$ & -117 & -149 & NS & 187 & -50 & $<0.01$ \\
\hline $\mathrm{PCO}_{2}$ ( $\left.\mu \mathrm{atm}\right)$ & -534 & -381 & NS & 850 & 26 & $<0.01$ \\
\hline
\end{tabular}

Table 9 Matrix of lake pairs versus the average synchrony values for 'major ions' $\left(\mathrm{Cond}, \mathrm{ALK}^{\mathrm{pH}}, \mathrm{DIC}^{\mathrm{Ca}}{ }^{2+}, \mathrm{Mg}^{2+}, \mathrm{Na}^{+}, \mathrm{K}^{+}, \mathrm{SO}_{4}{ }^{2-}\right.$ and $\left.\mathrm{Cl}^{-}\right)$in the upper right matrix, and for lake pairs versus the synchrony of 'nutrients' $\left(\mathrm{DOC} \mathrm{CO}_{2}, \mathrm{CH}_{4}, \mathrm{NH}_{4}^{+}, \mathrm{NO}_{3}^{-}, \mathrm{SRP}, \mathrm{TDN}^{\mathrm{PC}}\right.$, $\mathrm{PN}, \mathrm{PP}$ and $\mathrm{Chl} a$ ) in the lower left matrix

\begin{tabular}{|c|c|c|c|c|c|c|c|c|c|c|}
\hline & $\mathrm{I}-1$ & $\mathrm{I}-2$ & $\mathrm{I}-3$ & $\mathrm{I}-4$ & $\mathrm{I}-5$ & I-6 & $\mathrm{I}-7$ & $\mathrm{I}-8$ & I-Swamp & Toolik \\
\hline I-1 & - & 0.737 & 0.724 & 0.760 & 0.732 & 0.577 & 0.530 & 0.200 & 0.312 & 0.358 \\
\hline $\mathrm{I}-2$ & 0.494 & - & 0.494 & 0.703 & 0.697 & 0.465 & 0.437 & 0.138 & 0.412 & 0.261 \\
\hline $\mathrm{I}-3$ & 0.488 & 0.592 & - & 0.671 & 0.525 & 0.563 & 0.506 & 0.321 & 0.399 & 0.172 \\
\hline $\mathrm{I}-4$ & 0.464 & 0.574 & 0.672 & - & 0.801 & 0.608 & 0.587 & 0.194 & 0.279 & 0.294 \\
\hline I-5 & 0.525 & 0.536 & 0.580 & 0.644 & - & 0.664 & 0.595 & 0.212 & 0.523 & 0.269 \\
\hline I-6 & 0.492 & 0.623 & 0.577 & 0.549 & 0.693 & - & 0.620 & 0.343 & 0.741 & 0.440 \\
\hline $\mathrm{I}-7$ & 0.484 & 0.592 & 0.509 & 0.507 & 0.602 & 0.619 & - & 0.393 & 0.823 & 0.480 \\
\hline I-8 & 0.400 & 0.411 & 0.574 & 0.527 & 0.648 & 0.532 & 0.506 & - & 0.502 & 0.380 \\
\hline I-Swamp & 0.753 & 0.525 & 0.586 & 0.485 & 0.479 & 0.561 & 0.644 & 0.606 & - & 0.004 \\
\hline Toolik & 0.456 & 0.470 & 0.240 & 0.425 & 0.426 & 0.377 & 0.421 & 0.329 & 0.279 & - \\
\hline
\end{tabular}

Table 10 Spearman correlations for the relationship between the rank order of lakes (various morphological and landscape parameters) and the mean synchrony values across all lake pairs for different variables. The definitions of the 'major' and 'nutrient' variables are given in Table 9. For all correlations, $n=45$ lake pair combinations

\begin{tabular}{llll}
\hline Variable & $\begin{array}{l}\text { Spatial } \\
\text { proximity }\end{array}$ & $\begin{array}{l}\text { Catchment: } \\
\text { lake area }\end{array}$ & $\begin{array}{l}\text { Water residence } \\
\text { time }\end{array}$ \\
\hline All variables & $-0.55^{* *}$ & $-0.34^{*}$ & \\
'Major' variables & $-0.52^{* *}$ & $-0.36^{*}$ & \\
'Nutrient' variables & $-0.39^{* *}$ & & \\
Cond & $-0.45^{* *}$ & $-0.31^{*}$ & \\
pH & $-0.62^{* *}$ & & \\
$\mathrm{DIC}^{*}$ & & $-0.32^{*}$ & \\
$\mathrm{CO}_{2}$ & & & \\
$\mathrm{CH}_{4}$ & $-0.29^{*}$ & & \\
$\mathrm{NH}_{4}{ }^{+}$ & $-0.39^{* *}$ & & $-0.39^{* *}$ \\
$\mathrm{SRP}^{2+}$ & $-0.36^{*}$ & & \\
$\mathrm{Ca}^{2+}$ & $-0.80^{* *}$ & & \\
$\mathrm{SO}_{4}{ }^{2-}$ & & $-0.34^{*}$ & \\
\hline
\end{tabular}

${ }^{*} P<0.05$.

${ }^{*} P<0.01$.

(C) 2000 Blackwell Science Ltd, Freshwater Biology, 43, 477-497 some combination of the processes of: (1) evaporative concentration; (2) increased weathering through soilwater interactions; or (3) solute production or transformation (i.e. 'material processing'). Although quantifying the unique contributions of each of these effects in a landscape mass balance is beyond our data set, we can determine if such effects are likely to occur. For example, the water filling lakes lower in the chain will have passed through more soil, as represented by the cumulative catchment area, and this increased contact of water with soil or rock will result in higher concentrations of ions derived from weathering. To test if this explanation is plausible, we examined the relationship between chemical variables and the $C: L$ ratio, as well as the cumulative catchment area proceeding down the lake chain. Although altitude and cumulative catchment area are highly collinear (Pearson's $r=-0.98$ ), it is unlikely that altitude itself is causing these spatial patterns because of the small altitudinal change within the basin $(66 \mathrm{~m})$ 

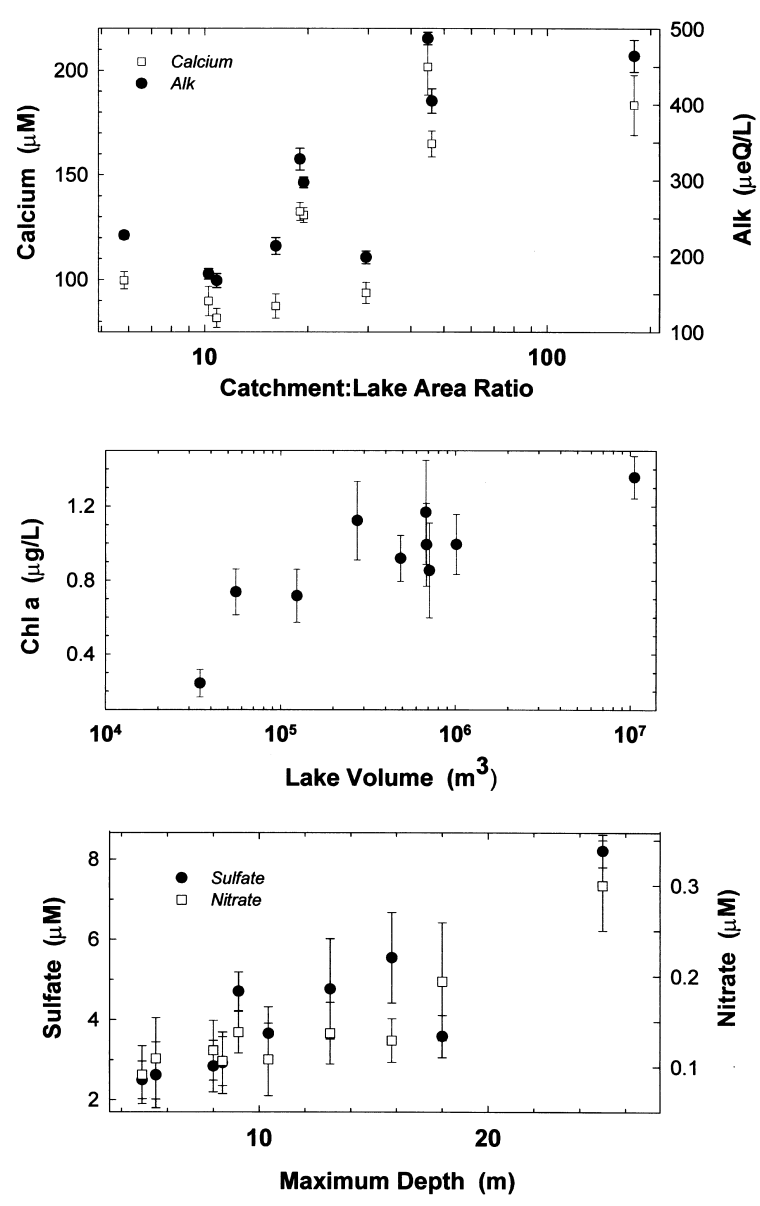

Fig. 4 Relationship of mean values of limnological variables and morphometric characteristics of the lakes and their catchments. The error bars represent the standard error (SE) of the mean.

and the lack of a mechanistic explanation related to altitude alone. The patterns seen in Fig. 2 were almost identical for all variables when plotted against the cumulative catchment area (data not shown). However, only $\mathrm{Ca}^{2+}$ and alkalinity were found to have significant relationships with C:L ratio (Pearson's $r=0.62, P<0.01$ and $r=0.70, P<0.01$, respectively; Fig. 4). This indicates that the relationship between weathering inputs and C:L area is more variable for any particular lake compared to the cumulative effects of increasing drainage area at lower altitudes, as can be seen by the weak relationship between lake position and $\mathrm{C}: \mathrm{L}$ versus the strong relationship between lake position and cumulative catchment area (Fig. 5).

Downslope patterns of decreasing concentrations of lake variables were limited to primary production and particulate nutrients in this study. Primary produc- tivity has been observed to increase moving down a lake chain (see Kratz et al., 1997; Elser \& Kimmel, 1985), but never to decrease. Although the decreasing trend is weak, in these ultra-oligotrophic lakes it is possible that the available nutrients are consumed in each lake and that this consumption is sufficient to lower the nutrient availability in successive lakes relative to the inputs from land. We have no evidence for this hypothesis at present, partly because inorganic nutrient concentrations in these surface waters are extremely low and difficult to measure accurately. However, this observation is consistent with data showing that the surrounding tundra vegetation is extremely limited by inorganic N and P (Shaver \& Chapin, 1980, 1991), and thus, the land would release these nutrients to receiving surface waters in very low concentrations (Kling, 1995). It is perhaps because of this strong terrestrial nutrient limitation that the lakes around Toolik and in the tundra region of Alaska are co-limited by $\mathrm{N}$ and $\mathrm{P}$ (Hobbie, 1980; Miller et al., 1986); such co-limitation is rare, but is also found in alpine tundra environments (Morris \& Lewis, 1988). In addition to the trend of primary productivity, the concentrations of particulate nutrients also showed a weak declining trend with decreasing lake altitude and a distinct alternating pattern of low to high concentrations from lake to lake (Fig. 3). This alternating pattern is similar to the pattern of primary production in the first six lakes and is consistent with the idea that higher rates of primary productivity lead to greater particulate concentrations; however, there was not a similar pattern with chl $a$ concentrations in these lakes.

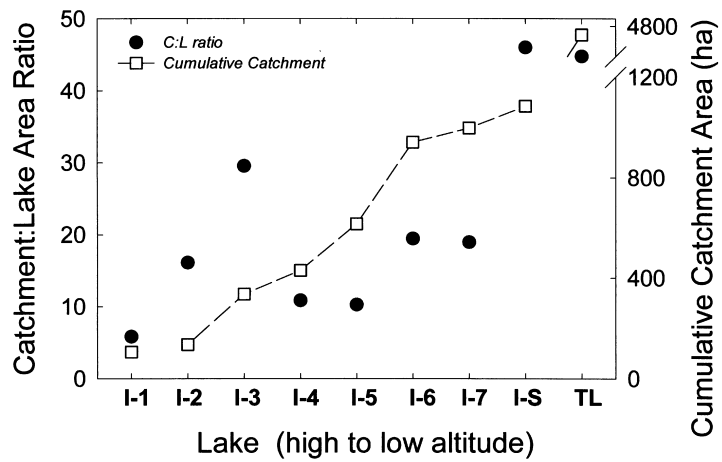

Fig. 5 Relationship between lake position on the landscape versus the catchment to lake area ratio $(\mathrm{C}: \mathrm{L})$ and the cumulative catchment area (data in Table 1). Lakes I-1 and I-2 are headwater lakes at the same altitude. Note the axis break for cumulative catchment area.

(C) 2000 Blackwell Science Ltd, Freshwater Biology, 43, 477-497 

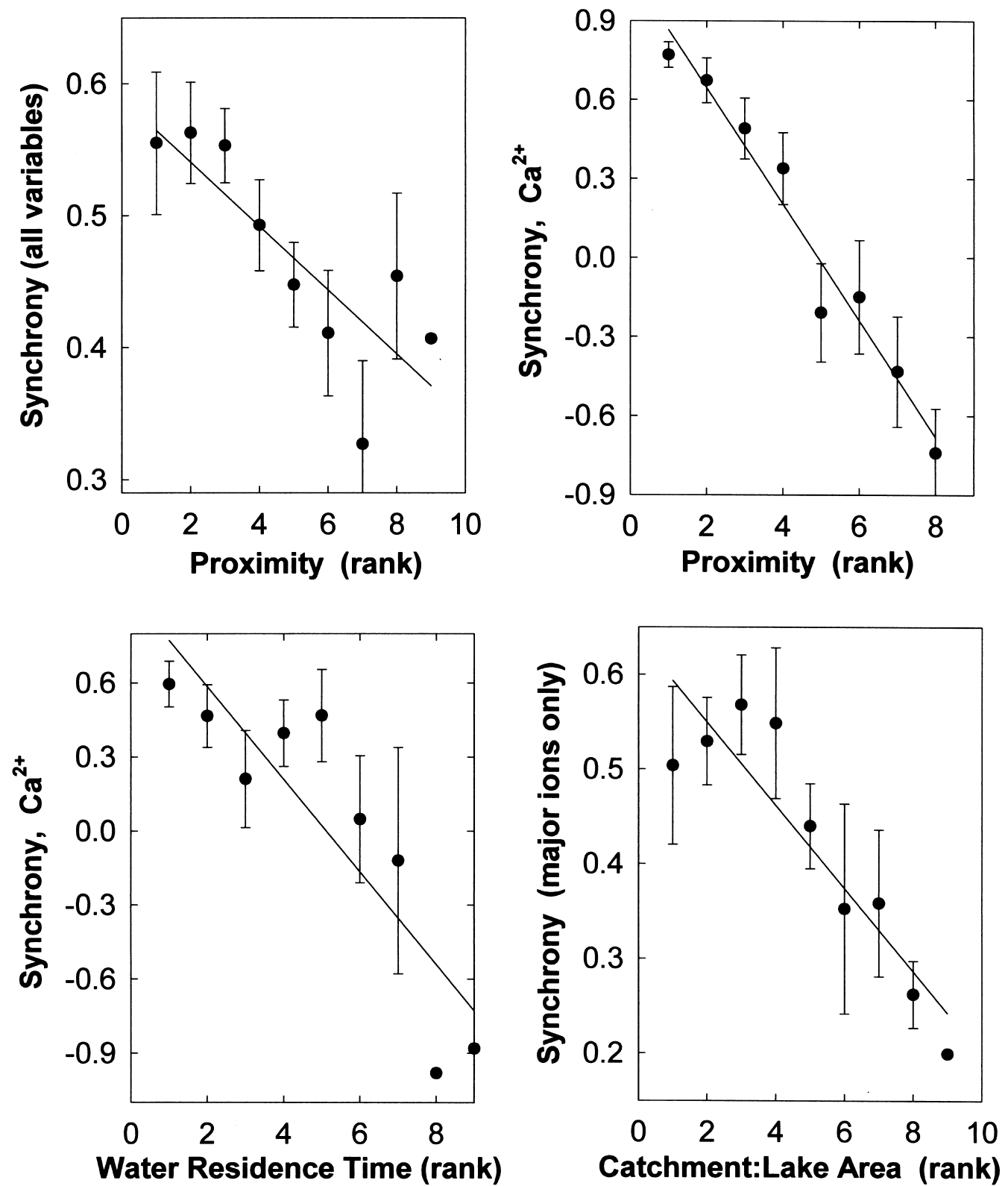

Fig. 6 Selected graphs of rank order of lake proximity, water residence time or catchment:lake area ratio plotted against mean synchrony values across all lake pairs for (a) all variables, (b) major ions only or (c) $\mathrm{Ca}^{2+}$ only. The error bars represent the standard error (SE) of the mean value for each rank on the $x$-axis. The trend line is given by least squares regression.

It is unlikely that these spatial relationships with solutes, particulates and primary production are confounded by the effects of lake morphometry. There were no strong relationships between spatial position of the lakes in the basin and lake morphometric descriptors such as area, depth, C:L ratio or volume (Table 1). In fact, we found only two relationships between the mean values of limnological variables and any measure of lake morphometry: (1) an increase in chl $a$ with increasing lake volume; and (2) an increase in the concentrations of $\mathrm{SO}_{4}{ }^{2-}$ and $\mathrm{NO}_{3}{ }^{-}$with maximum depth (Fig. 4). We have no data to suggest a mechanistic explanation for these relationships at present, although the lack of relationships between lake morphology and particular limnological characteristics of lake chains seems to be common (cf. Soranno et al., 1999). There are certainly a variety of processes affected by lake morphology, but 
492 G. W. Kling et al.

perhaps the range of lake morphologies in studies to date is too narrow for the processes strongly dependent on morphology to become dominant over those processes which are less dependent.

\section{Spatial patterns and material processing in lakes and streams}

Details of the spatial pattern of change in weathering ions with lake chain number can be related to the effects of catchment area, as described above, and also to the effects of material processing within lakes and in the connecting stream segments. Although a priori we expected no differences in the spatial patterns of change within the entire basin, there were in fact two regions of distinct response in the spatial patterns shown in Fig. 2. Firstly, there is a region of little change or very slight decrease in ion concentrations from lakes I-1 and I-2 down to I-5, and secondly, a region of strong increase in concentrations from Lake I-6 to the bottom of the chain at Toolik Lake. In the first region, the increases in cumulative catchment area are relatively small between each lake (Table 1 , Fig. 5; I-1 and I-2 are both headwater lakes feeding into I-3, and thus, their catchments are independent rather than additive). In addition, the processing of solutes and particulates within lakes is consistent from lake to lake, as is the material processing within the interconnecting stream segments, and what is consumed in lakes tends to be produced in streams (Table 5). Note that changes in solute concentrations in streams are apportioned in unknown amounts between seepage inputs from land and in-stream processing. Regardless of the relative apportionment, because the mass of material processed per unit volume is roughly balanced between lakes and streams, and because the cumulative catchment area increases only slowly in the upper region of the basin, the observed spatial pattern shows little change in ion concentrations from lake to lake.

In region 2, where ion concentrations rise, the relative increase in cumulative catchment area moving downstream is slightly larger than in region 1 , and the total increase is much larger (Table 1, Fig. 5). Thus, our mass balance prediction is that greater water-soil contact will increase the amount of ions derived from weathering. There also appears to be an effect of lake and stream processing. For example, the stream segments flowing into Lake I-6 and those found downstream tend to be longer in length than the connecting streams in the upper basin (mean of $244 \mathrm{~m}$ versus $470 \mathrm{~m}$; see Fig. 1). Correspondingly, these longer stream segments in region 2 tend to produce more ions on average than streams in region one. This higher production of weathering ions is statistically significant for alkalinity, $\mathrm{Ca}^{2+}, \mathrm{Mg}^{2+}$ and $\mathrm{pH}$ (Table 8). In addition, the lakes in region two tend to consume less alkalinity, $\mathrm{Ca}^{2+}$ and $\mathrm{Mg}^{2+}$ than the lakes in region one (Table 8 ). This may be a result of the fact that the lakes in region two have shorter water residence times than do the more upstream lakes (Table 1), and therefore, the amount of in-lake processing of ions is necessarily lower. We have no water flow data to use in solving a mass balance equation for these changes, but given the data in Table 8 , we see that, during passage through each of the four stream segments in region 2 , the water gains $\approx 19 \mu \mathrm{eq} \mathrm{L}^{-1}$ of alkalinity in each segment compared to region 1 , and in each of the three lakes in region 2 , $\approx 25 \mu \mathrm{eq} \mathrm{L}^{-1}$ less alkalinity is consumed (i.e. is 'gained' relative to lake processing in region one). The cumulative total is $\approx 151 \mu \mathrm{eq} \mathrm{L}^{-1}$ of increase in alkalinity from the downslope end of region one (Lake I-5) to the downslope end of region two at Toolik Lake; over this same distance, the measured increase in alkalinity concentration was $\approx 300 \mu \mathrm{eq} \mathrm{L}^{-1}$. Thus, the integrated changes caused by lake and stream processing are of the same order of magnitude as other processes, leading to increased solute concentrations in lakes as water moves through the basin, and are responsible in part for the spatial patterns shown in Fig. 2.

Consistent changes in lake or stream chemistry as a result of processing do not always result in spatial patterns. For example, there is no particular spatial pattern of dissolved $\mathrm{CO}_{2}$ and $\mathrm{CH}_{4}$ in either the lakes or streams in the basin, even though these gases are produced in significantly higher amounts in the shorter stream segments of region 1 than in the longer segments of region 2 (Table 8 ). This pattern is opposite of the pattern of higher ion concentrations in longer stream segments, and thus, somewhat counter-intuitive. For these gases, the longer stream segments provide greater opportunity for evasion to the atmosphere, and we have measured gas evasion rates in a section of the Toolik inlet stream an order of magnitude higher than in nearby lakes as a result of the turbulent nature of the stream (unpublished data). 
However, there was no significant relationship between gas concentrations and the length of stream segments in this study, which indicates that the balance between gas inputs in seepage, production or consumption in the stream, and rapid evasion to the atmosphere is established relatively quickly in time and space in any stream. This highlights a general conclusion that the effects of material processing are partly functions of varying spatial and temporal scales, as has been shown also for ecological processes in streams (Fisher, 1994; Cooper et al., 1998), and for the response of lake chemistry to climate forcing through drought (Webster et al., 2000). The specific causes of changes in materials as a result of 'processing' are varied, and while some are obvious, such as nutrient uptake, or the rapid degassing of $\mathrm{CO}_{2}$ and $\mathrm{CH}_{4}$ in streams, others may be more subtle and complex, such as the effects of food web structure on changes in chl $a$ concentrations or rates of biomass production. Even if such effects do not produce spatial patterns, these may be modelled with appropriate data as specific processes contributing to the landscape mass balance of chemical or biological variables.

\section{Synchrony in chemical and biological variables}

The average synchrony value of 0.50 across all variables in this study is slightly higher than averages reported for similar variables from Wisconsin lake districts (Magnuson et al., 1990; Baines et al., 2000), and slightly lower than most values reported for a variety of other lake districts (Webster et al., 2000; Soranno et al., 1999). These studies have also found that the more conservative major ions such as $\mathrm{Ca}^{2+}$ and $\mathrm{HCO}_{3}{ }^{-}$tend to have higher synchrony across all lakes than do the more bioreactive materials such as nutrients and chl $a$. We found no such consistent pattern, and as shown in Table 6, the nutrients and conservative ions have both high and low mean values of synchrony. In addition, when examined across lake pairs (Table 9), the 'major ions' had similar average synchrony values to the values for 'nutrients' for any given lake pair or for all pairs taken together. To understand why some groups of variables or lake districts have more or less synchrony, it is necessary to first understand the factors that affect synchrony.

Synchrony values indicate how individual or groups of variables behave over time at the scale of the entire lake district. In all studies of lake districts to date (cited above), synchrony values tend to be positive, indicating that groups of lakes respond similarly to external drivers such as climate. Internal drivers may also cause synchronous behaviour in particular lakes; for example, pelagic zooplankton densities may decrease over time as a result of predation only in lakes that contain fish, thus producing synchrony in those lakes when compared to nearby fishless lakes. Such internal drivers may ultimately be linked to external factors; for example, in this case, by cold winters causing thick ice which prevents fish from inhabiting shallow lakes (see also George \& Taylor, 1995). However, while spatial gradients of other features of the lake district such as underlying geology or landscape morphology may influence the nature of the response among lakes, these gradients cannot drive or cause high synchrony themselves. Negative synchrony values indicate that, on average, the response of an individual lake is opposite to that of other lakes on the landscape. Low synchrony values indicate some combination of three possible effects: (1) there may be very little change in the values of variables from one sampling time to another and synchrony is only produced if there is some variation over time; (2) weak drivers or low sensitivity of system behaviour to external drivers; or (3) the influence of strong spatial patterns of system behaviour within a district. The first and third effects can be easily identified. For example, the mean synchrony value for $\mathrm{Ca}^{2+}$ in this study was quite low (0.27), but there was a strong spatial pattern in individual comparisons of the highest lake in the basin, I-1, with other lakes moving down the drainage system (Table 7). For $\mathrm{Ca}^{2+}$, synchrony was strongly positive between I-1 and nearby lakes I-2 and I-3, low between $\mathrm{I}-1$ and lakes in the middle of the basin, and strongly negative between I-1 and lakes at the downstream end of the basin. Thus, a low mean value of synchrony across a lake district may be the result of averaging across a strong spatial gradient present at sub-district scales. Synchronous behaviour in any system forms a pattern of response, and our goal is to understand this behaviour by uncovering what processes or environmental factors influence the pattern or nature of the response.

\section{Spatial patterns of synchrony}

In this study, we found two main patterns of response when comparing the synchrony of lake behaviour for 
all variables in relation to landscape position, and to lake and landscape characteristics (Table 10). These main patterns are: (1) lakes close to one another have higher synchrony values than lakes more separated in space; and (2) synchrony of various major ions increases with increasing similarity of other characteristics of the lakes such as WRT and C:L ratio (Fig. 6). The first relationship between synchrony and spatial position is somewhat contrary to the findings of other studies, where the correlation between landscape position or horizontal proximity with the temporal synchrony of lake pairs was small in most cases (Magnuson et al., 1990; Soranno et al., 1999). The second relationship between synchrony and morphometric or hydrologic characteristics is similar to previous findings in other lake districts (Magnuson et al., 1990; Webster et al., 2000; Soranno et al., 1999).

The interpretation of these two relationships is based on the idea that the processing of materials moving across the landscape is important. For the first relationship, there must be some local effect unrelated to morphometry which causes lakes close to one another to behave similarly. For example, we assume that spatial position of the lakes is unrelated to regionalized variables (e.g. geology), landscape factors (e.g. catchment area) or lake morphometry. Therefore, a trend of synchrony with spatial position indicates the presence of some other local effect which is overriding or strongly influencing the drivers such as climate which produce positive synchrony at the scale of the entire lake district. In this study, the strong trends in synchrony and spatial position may be related to the local effect of consistent processing of materials as water moves through lakes and streams on the landscape. In effect, the chemical and biological make-up of the water is changing in a directional rather than random manner moving downslope. If this explanation is correct, we would expect that at least some of the variables showing significant changes in concentration from processing within stream segments or passing through lakes (from Table 5) would also be correlated with spatial proximity (from Table 10). All of the variables showing correlations with spatial proximity, except for SRP, also show significant in-lake or in-stream processing (i.e. conductivity, $\mathrm{Ca}^{2+}, \mathrm{pH}, \mathrm{CH}_{4}$ and $\mathrm{NH}_{4}{ }^{+}$). Although consistent changes as a result of processing do not insure a spatial pattern, as discussed above, there is still a substantial correspon- dence between variables with significant processing and variables showing strong correlations with spatial position. In river systems, there are similar patterns of material processing moving downstream (Vannote et al., 1980; Wiley, Osborne \& Larimore, 1990), but these patterns are often confounded by longitudinal changes in the physical structure of the river bed and the surrounding landscape. Here we show that, over relatively small geographic areas, and independent of lake or stream morphometry, the processing of materials can contribute to producing a spatial pattern which is coherent over time.

The second set of relationships showed that several variables had synchrony values significantly correlated with the rank order of lake or landscape morphology (C:L and WRT; Table 10). These relationships are also partly caused by material processing; an increase in WRT indicates greater time for internal lake processing, and an increase in C:L indicates a greater importance of the weathering process in the catchment and in the transfer of weathering products to the lake. In both cases, the processing and magnitude of transport of materials are the drivers, and C:L or WRT are the proxies for the resulting effect on synchrony. Significant relationships between synchrony and C:L or WRT indicate that these processing drivers have a substantial, additional effect on the behaviour of lakes over the effect of external climatic drivers. There is at least one complication with these interpretations because the correlation between the rank orders of WRT and C:L is positive and significant (rho $=0.53, P<0.001$ ). Lake pairs more similar in WRT are also more similar in $\mathrm{C}: \mathrm{L}$, which is expected because WRT is an approximate inverse function of C:L. Thus, separating the unique contributions of various processes to synchrony is difficult in this or any data set because: (1) the underlying processes are not always known; (2) the proxy measures used (such as WRT or landscape characteristics) may represent several different, interacting processes; or (3) the proxy measures may be correlated with one another. For example, in our data set, the synchrony value for $\mathrm{Ca}^{2+}$ among lake pairs was correlated both with proximity rank and with WRT rank (Fig. 6). In addition, the ranks of proximity and WRT were weakly correlated with each other (rho $=0.28$, $P=0.05)$. In this case, a stepwise multiple regression indicated that proximity rank alone accounted for $69 \%$ of the variance in $\mathrm{Ca}^{2+}$ synchrony and that WRT rank 
accounted for only an additional $6 \%$ of the variance (model $r^{2}=0.75, P<0.0001$ ). Given this, it appears that the combined effects of processing in lakes and streams are more important than in-lake processing alone in explaining the synchrony of $\mathrm{Ca}^{2+}$ in this lake district.

Placing these results in the context of a landscape mass balance may give some perspective on the differences and similarities with previous studies. In most landscapes, water flow is a strong link between ecosystems on land, between land and water, and between aquatic ecosystems. The relative importance of fluxes of materials to the system depends on the magnitude of inputs and outputs relative to the pool size of the material, and relative to the magnitude of processing within the pool. Relationships between synchrony and spatial position, as found in this study, indicate that the magnitude of material processing within each 'pool' (lake or stream) is large enough relative to other processes, and is consistent enough between similar pools on the landscape,to produce a pattern either in material concentrations, or in synchrony. The lack of a relationship between lake synchrony and spatial position, as found in some studies (Magnuson et al., 1990; Soranno et al., 1999), could be a result of insignificant processing, but also could be due to inputs to the system that overwhelm internal processing, or highly variable processing. For example, Soranno et al. (1999) described a lake district with distinct differences in geology, and thus, chemical inputs between lakes near the top versus near the bottom of the chain. In addition, in groundwater-dominated systems or systems where the WRT is large, intense or prolonged material processing may evolve heterogeneous pools of material on the landscape which have no consistent spatial pattern or do not respond to external drivers similarly, resulting in low synchrony. Note that material processing may be quite important to system functioning in these cases, but it simply does not contribute to spatial or temporal patterns. Finally, we would predict that synchrony and spatial patterns resulting from processing in surface waters will be most observable at time scales of years to decades, during which time shortterm variations in drivers or processing may be averaged to produce a mean response or observable pattern (e.g. our study lumped 7 years of data). Determining relevant time scales and the relative importance of material processing versus material fluxes, and linking those to patterns in time and space produced by system functioning, is possible through the modelling of landscape mass balance.

\section{Conclusion}

Individual ecological systems such as lakes or rivers are often studied intensively, and extrapolations are made to other, similar systems. Results from entire lake districts, for example, are averaged and compared to other regions of lakes. However, the gain in predictive knowledge resulting from these comparisons and extrapolations will be small unless we understand the specific processes controlling the spatial and temporal relationships within systems at fine scales (within a lake or stream), or at intermediate landscape scales which include relatively small numbers of lakes and rivers. At these intermediate scales, many ecological drivers such as climate and geological substrate are stationary or applied with equal force, and the processes which influence organisms or element cycling in relation to spatial position and the passing of time become more apparent. In this paper, we observed distinct spatial patterns in both the values of chemical and biological variables, and in the synchronous behaviour of these variables over time. In both cases, consistent changes in the concentrations of materials resulting from processing within lakes and within the stream segments connecting lakes were important contributors to the spatial patterns and lake synchrony.

It is unclear how generally important this spatially dependent material processing is in other systems. At the scale of large drainage basins which include many catchments $\left(10^{3}-10^{6} \mathrm{~km}^{2}\right)$, or across sharp gradients in environmental factors, the effects of material processing at scales of small basins or single catchments (10$100 \mathrm{~km}^{2}$ ) may be overwhelmed. However, given that the processing in lakes and streams had inverse yet equivalent effects on many variables in this study, we suggest that, when viewed in a spatially explicit manner, the linkages between land, lakes and streams may be more complex than previously understood. Just as characteristics such as hydrologic setting, or landscape and lake morphology have predictable influences on system functioning in a variety of lake districts (Soranno et al., 1999; Riera et al., 2000; Webster et al., 2000), we may find fundamental patterns or generalities in the influences of downslope 
processing. We suggest that a useful first approach to identifying these generalities is to understand the relative importance of various factors in a landscape mass balance context.

\section{Acknowledgments}

Many people assisted in the field work and lab analyses for this study over the years, especially Neil Bettez, Mark Brahce, Jacques Finlay, Tammy Gage, Bryan Harper, Megan Ridley, Alan Striegle and Peder Yurista. The data sets were collated and checked with the careful help of Karen Riseng, Mandy Barre, and N. Bettez. K. Riseng and M. Barre helped considerably with data analysis and graphing. We also thank Tim Kratz and two anonymous reviewers for useful criticisms and suggestions. This research was supported by NSF grants DEB-9211775, 9553064 and 9810222, and OPP-9400722 and 9615949.

\section{References}

Baines S.B., Webster K.E., Kratz T.K., Carpenter S.R. \& Magnuson J.J. (2000) Synchronous behavior of temperature, calcium and chlorophyll in lakes of northern Wisconsin. Ecology, in press.

Casti J.L. (1979) Connectivity, Complexity, and Catastrophe in Large-Scale Systems. John Wiley \& Sons, Chichester.

Chapra S.C. \& Reckhow K.H. (1983) Engineering Approaches for Lake Management, Vol 2: Mechanistic Modeling. Ann Arbor Science, Ann Arbor, MI.

Cliff A.D. \& Ord J.K. (1973) Spatial Autocorrelation. Pion Limited, London.

Cooper S.D., Diehl S., Kratz K. \& Sarnelle O. (1998) Implications of scale for patterns and processes in stream ecology. Australian Journal of Ecology, 23, 27-40.

Elser J.J. \& Kimmel B.L. (1985) Nutrient availability for phytoplankton production in a multiple-impoundment series. Canadian Journal of Fisheries Aquatic Science, 42, 1259-1370.

Fisher S.G. (1994) Pattern, process and scale in freshwater ecosystems: some unifying thoughts. Pattern, Process and Scale in Aquatic Ecology (Eds A. Hildrew, P. Giller \& D. Rafaelli), pp. 575-591. Blackwell Scientific Publications, Oxford.

Fisher S.G. \& Likens G.E. (1973) Energy flow in Bear Brook, New Hampshire: an integrative approach to stream ecosystem metabolism. Ecological Monographs, 43, 421-439.

George D.G. \& Taylor A.H. (1995) UK lake plankton and the Gulf Stream. Nature, 378, 139.
Hamilton T.D. \& Porter S.C. (1975) Itkillik glaciation in the Brooks Range, northern Alaska. Quaternary Research, 5, 471-497.

Hansen A.J. \& di Castri F. (Eds) (1992) Landscape Boundaries: Consequences for Biotic Diversity and Ecological Flows Springer-Verlag, Berlin.

Hansen A.J., Risser P.G. \& di Castri F. (1992) Biodiversity and ecological flows across ecotones. Landscape Boundaries: Consequences for Biotic Diversity and Ecological Flows (Eds A.J. Hansen \& F. di Castri), pp. 423-438. Springer-Verlag, Berlin.

Hanski I. \& Gilpin M. (1991) Metapopulation dynamics: a brief history and conceptual domain. Biological Journal of the Linnean Society, 42, 3-16.

Hargis C.D., Bissonette J.A. \& David J.L. (1998) The behavior of landscape metrics commonly used in the study of habitat fragmentation. Landscape Ecology, 13, 167-186.

Hinzman L.D., Kane D.L., Gieck R.E. \& Everett K.R. (1991) Hydrologic and thermal-properties of the active layer in the Alaskan Arctic. Cold Regions Science and Technology, 19, 95-110.

Hobbie J.E. (Ed.) (1980) Limnology of Tundra Ponds. Dowden, Hutchinson \& Ross, Inc., Stroudsburg.

Kling G.W. (1995) Land-water linkages: the influence of terrestrial diversity on aquatic systems. The Role of Biodiversity in Arctic and Alpine Tundra Ecosystems (Eds F.S. Chapin \& C. Korner), pp. 297-310. SpringerVerlag, Berlin.

Kling G.W., Kipphut G.W. \& Miller M.C. (1991) Arctic lakes and rivers as gas conduits to the atmosphere: implications for tundra carbon budgets. Science, 251, 298-301.

Kling G.W., Kipphut G.W. \& Miller M.C. (1992b) The flux of carbon dioxide and methane from lakes and rivers in arctic Alaska. Hydrobiologia, 240, 23-36.

Kling G.W., O’Brien W.J., Miller M.C. \& Hershey A.E. (1992a) The biogeochemistry and zoogeography of lakes and rivers in arctic Alaska. Hydrobiologia, 240, 1-14.

Kratz T.K., Benson B.J., Blood E.R., Cunningham G.L. \& Dahlgren R.A. (1991) The influence of landscape position on temporal variability in four North American ecosystems. American Naturalist, 138, 355-378.

Kratz T.K., Webster K.E., Bowser C.J., Magnuson J.J. \& Benson B.J. (1997) The influence of landscape position on lakes in northern Wisconsin. Freshwater Biology, 37, 209-217.

Langner C.L. \& Hendrix P.F. (1982) Evaluation of a persulfate digestion method for particulate nitrogen and phosphorus. Water Research, 16, 1451-1454.

Legendre P. \& Fortin M. (1989) Spatial pattern and ecological analysis. Vegetatio, 80, 107-138.

(C) 2000 Blackwell Science Ltd, Freshwater Biology, 43, 477-497 
Lerman A. (1972) Strontium 90 in the Great Lakes: concentration-time model. Journal of Geophysical Research, 77, 3256-3264.

Levin S.A., Powell T.M. \& Steele J.H. (Eds) (1993) Patch Dynamics. Springer-Verlag, Berlin.

Levins R. (1969) Some demographic and genetic consequences of environmental heterogeneity for biological control. Bulletin of the Entomological Society of America, 15, 237-240.

Magnuson J.J., Benson B.J. \& Kratz T.K. (1990) Temporal coherence in the limnology of a suite of lakes in Wisconsin, U.S.A. Freshwater Biology, 23, 145-159.

Miller M.C., Hater G.R., Spatt P., Westlake P. \& Yeakel P. (1986) Primary production and its control in Toolik Lake. Alaska Archiv Hydrobiologie, 74 (Suppl.), 97-134.

Moloney K.A., Morin A. \& Levin S.A. (1991) Interpreting ecological patterns generated through simple stochastic processes. Landscape Ecology, 5, 163-174.

Morris D.P. \& Lewis W.M. (1988) Phytoplankton limitation in Colorado mountain lakes. Freshwater Biology, 20, 315-327.

Newbold J.D., Elwood J.W., O'Neill R.V. \& Van Winkle W. (1981) Measuring nutrient spiralling in streams. Canadian Journal of Fisheries Aquatic Science, 38, 860863.

O'Brien W.J., Bahr M., Hershey A., Hobbie J., Kipphut G., Kling G., Kling H., McDonald M., Miller M., Rublee P. \& Vestal R. (1997) The limnology of Toolik Lake. Alaskan Freshwaters (eds A. Milner \& M.W. Oswood), pp. 61-106, Springer-Verlag, Berlin.

O’Neill R.V., DeAngelis D.L., Waide J.B. \& Allen T.F.H. (1986) A Hierarchical Concept of Ecosystems. Princeton University Press, Princeton, NJ.

Platt T. \& Denman K.L. (1975) Spectral analysis in ecology. Annual Review of Ecology Systematics, 6, 189210.

Powell T.M. \& Steele J.H. (Eds) (1995) Ecological Time Series. Chapman \& Hall, London.

Riera J.L., Magnuson J.J., Kratz T.K. \& Webster K.E. (2000) A geomorphic template for the analysis of lake districts applied to the northern highland lake district, Wisconsin, USA. Freshwater Biology, 43, 301-318.

Shaver G.R. \& Chapin F.S., III (1980) Response to fertilization by various plant growth forms in the Alaskan tundra: nutrient accumulation and growth. Ecology, 61, 662-675.

Shaver G.R. \& Chapin F.S., III (1991) Production:biomass relationships and element cycling in contrasting arctic vegetation types. Ecological Monographs, 61, 1-31.

Soranno P.A., Webster K.E., Riera J.L., Kratz T.K., Baron
J.S., Bukaveckas P.A., Kling G.W., White D.S., Caine N., Lathrop R.C. \& Leavitt P.R. (1999) Spatial variation among lakes within landscapes: ecological organization along lake chains. Ecosystems, 2, 395-410.

Swanson F.J., Kratz T.K., Caine N. \& Woodmansee R.G. (1988) Landform effects on ecosystem patterns and processes. Bioscience, 38, 92-98.

Taylor P.D., Fahrig L., Henein K. \& Merriam G. (1993) Connectivity is a vital element of landscape structure. Oikos, 68, 571-573.

Turner M.G. \& Gardner R.H. (1991) Quantitative Methods in Landscape Ecology. Springer-Verlag, Berlin.

Vannote R.L., Minshall G.W., Cummins K.W., Sedell J.R. \& Cushing C.E. (1980) The river continuum concept. Canadian Journal of Fisheries Aquatic Science, 37, 130-137.

Vollenweider R.A. (1975) Input-output models with special reference to the phosphorus loading concept in limnology. Schweizerische Zeitschrift Hydrologie, 37, 53-84.

Vörösmarty C.J., Meybeck M., Fekete B. \& Sharma K. (1997b) The potential impact of neo-Castorization on sediment transport by the global network of rivers. Human Impact on Erosion and Sedimentation (Eds D. Walling \& J.-L. Probst), pp. 261-272. IAHS Press, Wallingford.

Vörösmarty C.J., Sharma K., Fekete B., Copeland A.H., Holden J., Marble J. \& Lough J.A. (1997a) The storage and aging of continental runoff in large reservoir systems of the world. Ambio, 26, 210-219.

Ward J.V. \& Standford J.A. (1983) The serial discontinuity concept of lotic ecosystems. Dynamics of Lotic Ecosystems (Eds T.D. Fontaine \& S.M. Bartell), pp. 2942. Ann Arbor Science, Ann Arbor, MI.

Webster K.E., Soranno P.A., Baines S.B., Kratz T.K., Bowser C.J., Dillon P.J., Campbell P., Fee E.J. \& Hecky R.E. (2000) Structuring features of lake districts: geomorphic and landscape controls on lake chemical responses to drought. Freshwater Biology, 43, 499-515.

Wiley M.J., Osborne L.L. \& Larimore R.W. (1990) Longitudinal structure of an agricultural prairie river system and its relationship to current stream ecosystem theory. Canadian Journal of Fisheries Aquatic Science, 47, 373-383.

With K.A. (1997) The application of neutral landscape models in conservation biology. Conservation Biology, 11, 1069-1080.

(Manuscript accepted June 1999) 